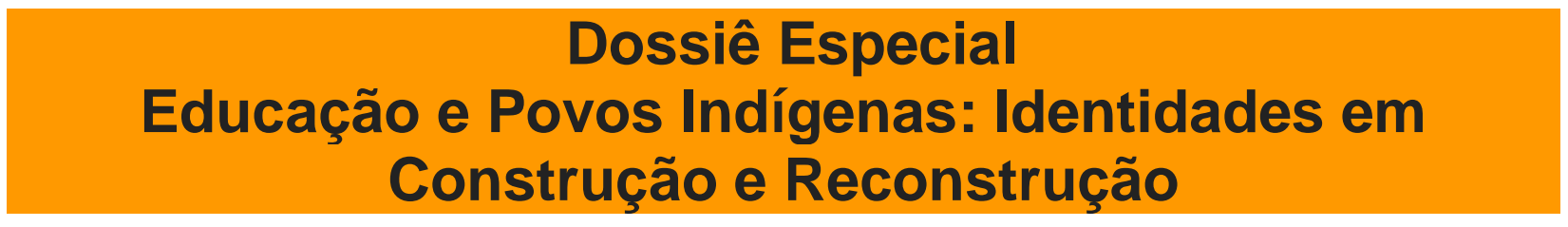

arquivos analíticos de políticas

\title{
educativas
}

Revista acadêmica, avaliada por pares, independente, de acesso aberto, e multilíngue

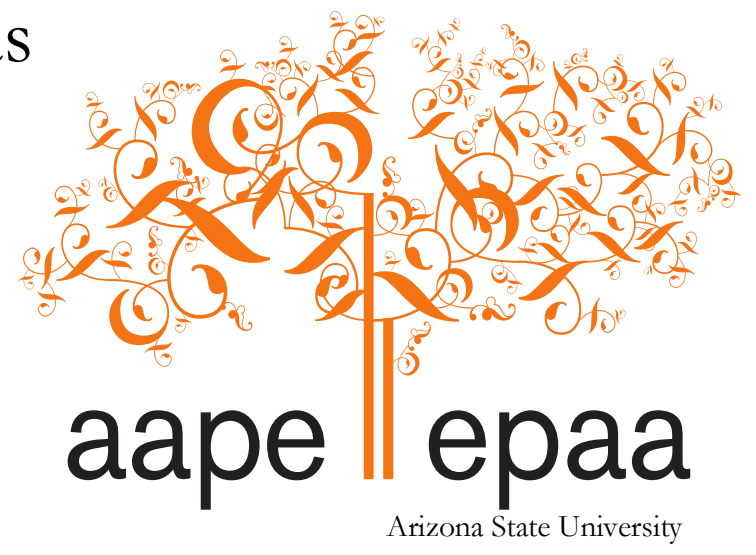

Volume 28 Número 81

11 de maio de 2020

ISSN 1068-2341

\section{O Lugar das Matemáticas na Formação de Professores Indígenas da Região do Alto Solimões/AM}

\author{
Elisângela Aparecida Pereira de Melo \\ Universidade Federal do Tocantins (UFT) \\ \& \\ Gerson Ribeiro Bacury \\ Pedro Ferreira da Silva \\ \&o \\ Domingos Anselmo Moura da Silva \\ Universidade Federal do Amazonas (UFAM) \\ Brasil
}

Citação: Melo, E. A. P de., Bacury, G. R., Silva, P. F da., \& Silva, D. A. M da. (2019). O lugar das matemáticas na formação de professores indígenas da região do Alto Solimões/AM. Arquivos Analiticos de Politicas Educativas, 28(81). https://doi.org/10.14507/epaa.28.4773 Este artigo faz parte do dossiê especial, Educação e Povos Indígenas - Identidades em Construção e Reconstrução, editado por Juliane Angnes e Kaizo Iwakami Beltrao.

Resumo: O presente artigo aborda as práticas matemáticas no Curso de Licenciatura em Formação de Professores Indígenas da Universidade Federal do Amazonas/Câmpus de Benjamin Constant, num contexto de diversidade cultural e linguística. Para a reflexão acerca dessa temática, tomamos como ponto de partida a seguinte indagação: Em que termos formativos as práticas matemáticas, via Material Concreto, repercutem nos modos de ensinar e 
aprender dos discentes indígenas da turma do Alto Solimões/UFAM? Nesse sentido, objetivamos descrever as distintas abordagens metodológicas quanto ao ensino e a aprendizagens de alguns conceitos no âmbito da Geometria Plana, junto aos estudantes indígenas do Curso de Licenciatura em Formação de Professores Indígenas/UFAM. O estudo possui uma abordagem qualitativa pautada na pesquisa etnográfica, tendo como recolha e análise de informações: as impressões, as percepções e os episódios junto aos colaboradores, assim como as atividades interdisciplinares, intraculturais e interculturais potencializadas na compreensão de alguns conceitos da Geometria Plana, com destaque para as cestarias das artesãs Ticuna. Nossas reflexões evidenciam, dentre outras coisas, a aquisição de novos conhecimentos, a criação, a elaboração e a proposição de distintas atividades e práticas matemáticas para as ações docentes futuras nas escolas de suas comunidades.

Palavras-chave: Formação de professores indígenas; povos indígenas do Alto Solimões; geometria plana; cestarias Ticuna; matemáticas do cotidiano escolar indígena

\section{The place of mathematics in the training of indigenous teachers in the Alto Solimões Region/AM}

Abstract: This article approaches the mathematical practices in the Degree Course in Indigenous Teacher Training of the Federal University of Amazonas/Campus of Benjamin Constant, in a context of cultural and linguistic diversity. For reflection on this theme, we take as a starting point the following question: In what formative terms the mathematical practices, through Concrete Material, have repercussions in the ways of teaching and learning of the indigenous students of the group of Alto Solimões/UFAM? In this sense, we aim to describe the different methodological approaches to the teaching and learning of some concepts in the scope of Flat Geometry, together with the indigenous students of the Undergraduate Course in Training of Indigenous Teachers/UFAM. The study has a qualitative approach based on ethnographic research, with the collection and analysis of information: impressions, perceptions and episodes with employees, as well as interdisciplinary, intracultural and intercultural activities enhanced in the understanding of some concepts of Flat Geometry, with emphasis on the baskets of the Ticuna artisans. Our reflections show, among other things, the acquisition of new knowledge, the creation, elaboration and proposition of different activities and mathematical practices for the future teaching actions in the schools of their communities.

Keywords: Training of indigenous teachers; indigenous peoples of Alto Solimões; flat geometry; Ticuna baskets; mathematics of indigenous school daily life

\section{E1 lugar de las matemáticas en la formación de docentes indígenas en la región de Alto Solimões/AM}

Resumen: Este artículo aborda las prácticas matemáticas en la Licenciatura en Capacitación de Maestros Indígenas de la Universidad Federal de Amazonas/Campus de Benjamin Constant, en un contexto de diversidad cultural y lingüística. Para reflexionar sobre este tema, tomamos como punto de partida la siguiente pregunta: ¿En qué términos formativos las prácticas matemáticas, a través del material concreto, tienen un impacto en las formas de enseñanza y aprendizaje de los estudiantes indígenas de la clase Alto Solimões/UFAM? En este sentido, nuestro objetivo es describir los diferentes enfoques metodológicos para la enseñanza y el aprendizaje de algunos conceptos dentro del alcance de la Geometría Plana, con los estudiantes indígenas del Curso de Grado en Formación de Maestros Indígenas/UFAM. El estudio tiene un enfoque cualitativo basado en la investigación etnográfica, con la recopilación y análisis de información: impresiones, percepciones y episodios con los empleados, así como actividades interdisciplinarias, intraculturales e interculturales mejoradas en la comprensión de algunos conceptos de geometría plana, con énfasis en las canastas de artesanos 
Ticuna. Nuestras reflexiones muestran, entre otras cosas, la adquisición de nuevos conocimientos, la creación, elaboración y propuesta de diferentes actividades y prácticas matemáticas para futuras acciones de enseñanza en las escuelas de sus comunidades. Palabras-clave: Entrenamiento de maestros indígenas; pueblos indígenas de Alto Solimõ es; geometría plana; cestería Ticuna; matemáticas de la rutina escolar indígena

\section{Introdução}

A reflexão a que nos propomos neste texto tem suas bases conceituais, didáticas e pedagógicas em nossas práticas docentes como "professores-formadores-pesquisadoresorientadores" (Bacury, 2018) no Curso de Licenciatura em Formação de Professores Indígenas da Universidade Federal do Amazonas (UFAM), na área de Ciências Exatas e Biológicas, mais precisamente quanto ao ensino de Matemática. Essas reflexões foram traçadas durante o desenvolvimento da disciplina "Fundamentos de Matemática Elementar II", ministrada aos professores indígenas em formação inicial da turma do Alto Solimões - que tem como polo o município de Benjamin Constant, no estado do Amazonas/AM.

Destacamos que o Curso vem se desenvolvendo desde 2008, tendo formado três turmas e nos tempos atuais atende a outras quatro turmas, a saber: Alto Rio Negro, Manicoré, Lábrea e Médio Solimões (em fase de conclusão). É nesse contexto de diversidade que se desenvolvem nossas práticas matemáticas, de modo a contribuir para formar, em nível superior, numa perspectiva intercultural e interdisciplinar, professores indígenas para atuarem nos seguimentos do Ensino Fundamental e Médio.

Para tanto, evidenciaremos as práticas com materiais didáticos a partir do uso de Materiais Concretos no estudo de alguns conceitos no campo da Geometria Plana, de modo a levar aos discentes os conhecimentos matemáticos visando, dentre outros objetivos, ao atendimento ao anseio desses povos quanto ao acesso à escolarização em todos os níveis, no intuito de promover os “[...] direitos indígenas, na medida em que permitem a apropriação dos conhecimentos e tecnologias do mundo moderno capazes de contribuir para a melhoria das condições de vida em suas aldeias [...]" (Baniwa, 2009, p.26), sem esquecer que esse processo de formação precisa, sempre que possível, privilegiar a diversidade cultural e suas peculiaridades.

A partir dessas compreensões, indagamos neste estudo: Em que termos formativos as práticas matemáticas, via Material Concreto, repercutem nos modos de ensinar e aprender dos discentes indígenas da turma do Alto Solimões/UFAM? É importante destacar que levaremos em consideração as interconexões entre a Matemática Acadêmica, a Matemática Escolar, a Matemática do Cotidiano; e, a partir dos contextos comunitários dos povos, a Matemática do Cotidiano Escolar Indígena.

Nessa direção, como fio condutor na busca da(s) possiblidade(s) de resposta(s) a essa questão, objetivamos descrever as distintas abordagens metodológicas quanto ao ensino e às aprendizagens de alguns conceitos no âmbito da Geometria Plana junto aos estudantes indígenas do Curso de Licenciatura em Formação de Professores Indígenas/UFAM.

Posto isso, recorreremos, inicialmente, a conhecer o contexto no qual ocorreram as atividades, em seguida, desatacaremos alguns elementos pertinentes aos desafios da formação de professores indígenas, buscando desvendar suas interconexões e refletir sobre a função que esse processo desempenha nas práticas formativas com a Matemática a partir da implementação de metodologias de ensino voltadas para o ensino e aprendizado de alguns conceitos da Geometria Plana. 


\section{Os Povos Indígenas do Alto Solimões-AM}

Para além de suas dimensões continentais, o Brasil é um país multicultural e rico em diversidade cultural e linguística, onde se encontra a realidade sociocultural dos 305 povos indígenas falantes de mais de 274 línguas diferentes entre si, que muitas vezes são "[...] tão diversas e incompreensíveis entre si quanto o português e o chinês.” (Brasil/RCNEI, 2005, p. 22). Desse contexto sociocultural dos povos indígenas brasileiros, conforme indica o último censo realizado pelo IBGE (Brasil, 2010), é no estado do Amazonas que está concentrada a maior população indígena, cerca de 119 mil habitantes, distribuídos na zona urbana e rural de diversos municípios amazonenses.

Além disso, concentra-se no estado do Amazonas a maior população de indígenas por povo, com destaque para os Ticuna, com aproximadamente 41 mil, distribuídos em vinte e seis terras indígenas na região do Alto Solimões, que somados aos demais povos indígenas da região resultam em uma população de cerca de 76 mil indígenas distribuídos em 350 comunidades/aldeias pertencentes a 18 povos que são: os Ticuna, os Kokama, os Kambeba, os Caixana, os Kanamari, os Witota, os Katukina, os Madja-Kulina, os Mura, os Maku, os Makuna, os Kaku-yuhup, os AvaCanoeiro, os Miranha, os Mayuruna, os Desana, os Tukano e os Tuyuka ${ }^{1}$.

Ademais, o estado do Amazonas também abriga outros 65 povos que, juntamente com os Ticuna, são falantes de mais de 29 línguas, constituindo, assim, um contexto cultural e linguístico por meio da pluriculturalidade dos saberes e fazeres tradicionais indígenas. Nesse contexto linguístico, destacam-se os povos que vivem em regiões de fronteiras, contribuindo assim para a aprendizagem de outras línguas como o espanhol.

Quanto ao espaço físico onde ocorrem os processos formativos e educativos do Curso de Licenciatura em Formação de Professores Indígenas/UFAM, com destaque à turma do Alto Solimões, destaca-se que o referido curso tem como polo o município de Benjamin Constant. A distância entre o município e a capital Manaus é de aproximadamente $1.119 \mathrm{~km}$ em linha reta, sendo que o deslocamento por transporte aéreo se realiza dentro de um espaço de tempo de 1 h 50 min, já por via fluvial (barco), a distância é de $1.575 \mathrm{~km}$, correspondendo a 12 dias de viagem.

Essa região está localizada na fronteira tríplice entre Brasil, Colômbia e Peru, sendo formada pelos municípios de Benjamin Constant, Tabatinga, Atalaia do Norte, Tonantins, Santo Antônio do Içá, São Paulo de Olivença, Amaturá, Jutaí e Fonte Boa. Vale ressaltar que o município de Benjamin Constant, segundo o IBGE (Brasil, 2010), possui uma população de aproximadamente 33 mil habitantes, destes, cerca de 10 mil são indígenas.

No que concerne ao Curso, atualmente constam nos registros da turma do Alto Solimões 42 estudantes regularmente matriculados, destes, 33 são pertencentes ao povo Ticuna, residentes na região. De acordo com os estudos de Ibarra \& Souza (2016, p. 98), "Os Ticuna se autodenominam como Magüta, que quer dizer 'povo pescado com vara', o que remete à história do seu mito de criação. Seu lugar de origem é o Igarapé Eware, no Brasil. Ali, os heróis míticos Yoi e Ipi pescaram o povo Ticuna e os demais povos existentes". Ademais, além de sua língua materna - Ticuna, também falam o português e o espanhol.

Os outros 9 estudantes são pertencentes ao povo indígena Kokama, que vivem juntamente com os Ticuna na região do Alto Solimões, porém em suas próprias comunidades, mas compartilham entre si saberes e fazeres originários dos povos indígenas. Há, ainda, uma relação interétnica por meio dos casamentos entre indígenas Ticuna e Kokama.

\footnotetext{
${ }^{1}$ Para mais informações, consultar: http://www.funai.gov.br/index.php/apresentacao-solimoes. Acessado em 20 de maio de 2019.
} 
Importa dizer que esses povos têm sua subsistência garantida por meio da produção de roças, onde plantam os principais alimentos, assim como a pesca e a caça, que garantem a segurança alimentar de todo o núcleo familiar, além da produção e confecção de artesanatos.

Dos seus saberes e dos fazeres originários, damos destaque à produção de artesanatos, em especial as cestarias com as fibras extraídas das palmeiras do arumã, do tucumã e de outras plantas nativas em seu território, trazendo a vida e a história do povo Ticuna, como destaca os estudos de Costa (2018, p. 32):

Nosso posicionamento dialógico frente ao processo de confecção da cestaria Ticuna, particularmente dos cestos, nos permite dizer que esses objetos são parte de uma cultura complexa que constrói e reconstrói conhecimentos que ultrapassam os conhecimentos próprios da cultura Ticuna, uma vez que representam as talas, fios e fibras de uma trama que conforma parte da vida desse povo, representa sua história, bem como expressa uma forma particular de pensar o mundo e se vê como integrante dele.

Essas cestarias integram a vida diária dos indígenas, são por eles usadas para diversos fins, desde os domésticos - para guardar alimentos, objetos pessoais e outros, para a comercialização - até os fins de geração de renda financeira e por partes das mulheres, as principais e hábeis artesãs em suas comunidades, constituindo-se como "[...] referência à identidade social, isto, porque saber confeccionar cestos é um requisito para se tornar uma 'boa mulher Ticuna', mas, também é fonte de sustento para muitas famílias.” (Costa, 2018, p. 137, apud Costa, 2012)

Da produção e diversidade das cestarias nos contextos comunitários indígenas, temos que a vida diária, os elementos e os seres que compõem a natureza e seus modos de conceber a vida se misturam por entre os diferentes desenhos e símbolos presentes nesses cestos.

De mesmo modo, ocorre nas pinturas corporais e faciais um verdadeiro sistema de relação, de identidade, de revitalização e de afirmação entre os indígenas e o meio ambiente, o céu, a terra, a água, o fogo e tantos outros traços, que permitem o entrecruzar a oralidade, o silêncio, o observar, o aprender e o fazer na prática de uma arte repassada de geração a geração, preservando nessa transmissão de conhecimentos os saberes originários de uma vida de ser indígena, face aos conhecimentos mobilizados pelo contato direto e indireto com os não indígenas.

Nessa perspectiva, apontamos as distintas leituras socioculturais realizadas pelos indígenas Ticuna e Kokama no transcorrer do Curso de Licenciatura em Formação de Professores Indígenas/UFAM sobre suas aprendizagens socioculturais e suas formas originárias de manterem vivas as suas tradições em um processo de construção de novos conhecimentos.

Ademais, as propositivas e especificidades formativas e educativas do Curso de Licenciatura em Formação de Professores Indígenas/UFAM, passaremos a discutir na próxima seção.

\section{O Curso de Licenciatura em Formação de Professores Indígenas/UFAM}

O Curso de Licenciatura em Formação de Professores Indígenas/UFAM, que está em funcionamento desde 2008, configura-se como uma possibilidade de ampliação da atuação desta Instituição de Ensino Superior (IES) junto aos povos indígenas do Amazonas - respondendo ao desafio institucional de contribuir para a formação específica de professores indígenas que atuarão nas escolas de suas aldeias.

A construção deste Projeto Político-Pedagógico (PPP), que visa a uma ação específica de ensino, vem se realizando num processo participativo que tem, como princípio, ouvir as 
comunidades, indo às aldeias, reunindo a população indígena destas para discutir, debater e construir o projeto de formação que lhes interessa.

É nessa perspectiva que o projeto inicial do Curso é discutido com a participação intensa dos povos indígenas por meio de suas lideranças, de modo que essas discussões têm possibilitando o diálogo sobre suas necessidades, aspirações frente à escolarização, o projeto de escola que os povos indígenas desejam/almejam e a formação de seus professores.

Esse quereres são reforçados pelas falas de lideranças e professores indígenas:

Nossa expectativa é que se realize esse curso para que nós professores possamos melhorar a nossa prática de ensino em sala de aula para que nossos alunos tenham mais conhecimentos quanto à educação (Escola Dr. Jacobina, povo Mura).

[...]. Queremos a licenciatura para aperfeiçoar e ampliar mais o nosso conhecimento pedagógico (Escola Novo Horizonte, povo Mura).

Queremos um curso específico e de qualidade, que venha aprimorar cada vez mais os nossos conhecimentos (Escola Capitão Getúlio e Escola Sete de Setembro, povo Mura).

Dentro da legalidade, temos direito ao Ensino Superior. A educação é um bem. As leis protegem, amparam, por isso o povo Sateré-Mawé solicitou o Ensino Superior. A educação é um direito e também é um bem (Prof. Euzébio Torquato, povo Sateré-Mawé).

Através do ensino superior podemos realizar novas conquistas e podemos ampliar as técnicas e conhecimentos da cultura do povo Sateré-Mawé (Satere Ywania, povo Sateré-Mawé).

O ensino superior irá formar professores comprometidos com a realidade sociocultural do seu povo, incentivando os outros Sateré a fortalecerem seus costumes, histórias, cultura e educação (povo Sateré-Mawé).

Precisamos ter um ensino superior específico para professores indígenas para formar nossos alunos dentro de nossas terras. Porque nem todos, quando concluem o $5^{\circ}$ ano de estudo, têm condições de se deslocar para as cidades e avançar nos estudos (Grupo de Trabalho - Satere Ywaria, povo Sateré-Mawé).

Fonte: Brasil/PPP/UFAM, 2012.

Uma parte importante e decisiva nesse processo refere-se à construção da Matriz Curricular do Curso e de suas adequações por Turmas/Povos, que é a definição de uma política linguística específica - problematizando a questão do ensino da Língua Portuguesa e das Línguas Maternas de cada povo indígena - sempre respeitando a situação sociolinguística de cada povo. Assim, o Curso de Licenciatura em Formação de Professores Indígenas/UFAM tem por objetivo geral:

Formar, em nível superior, numa perspectiva intercultural e interdisciplinar, professores indígenas para atuar na $2^{\mathrm{a}}$ etapa do ensino fundamental e no ensino médio, nas escolas indígenas, com habilitação plena nas áreas de Ciências Humanas e Sociais; Ciências Exatas e Biológicas; Letras e Artes. (Brasil/PPP/UFAM, 2012, p. 14)

E como objetivos específicos: 
Contribuir para o avanço do projeto político-pedagógico das escolas indígenas; Oferecer condições para que as escolas indígenas, através do trabalho educativo integrado dos professores e comunidades, possam promover o acesso aos saberes científicos historicamente construídos pela humanidade, bem como a valorização do patrimônio territorial, cultural e ambiental indígena, propiciando um diálogo intercultural, a partir de suas lógicas e valores; Possibilitar aos professores indígenas um processo de formação que contribua para a construção de condições de promover em sala de aula o processo educativo que, fundamentado na cultura e forma de pensamento própria de cada povo, possa estar orientado para a melhoria das condições de vida, através da apropriação crítica de bens culturais e recursos tecnológicos advindos de outras sociedades; e, Promover ações que permitam a indissociabilidade entre o ensino, a pesquisa e a extensão. (Brasil/PPP/UFAM, 2012, p. 14)

Ademais, esse Curso tem, como princípios norteadores e balizadores de aprendizagens, ações voltadas para a interculturalidade - do diálogo entre as diferentes histórias e saberes e a possibilidade de seleção/escolha conjunta (Universidade e organizações indígenas) das disciplinas e conteúdos que compõem o currículo do curso.

A perspectiva da interculturalidade é indicada no Referencial para Implantação de Programas de Formação de Professores Indígenas nos Sistemas Estaduais de Ensino (Brasil, 2001), destacando a importância de elaboração de propostas destinadas à Formação Continuada e à Licenciatura, em nível superior, especificamente na educação intercultural e bilíngue.

Com base em nossas vivências como professores-formadores-pesquisadores-orientadores de professores indígenas com habilitação na área de Ciências Exatas e Biológicas do Curso de Licenciatura em Formação de Professores Indígenas/UFAM, a interculturalidade requer de nós a criatividade, o respeito às práticas com o uso da língua materna e a relação teoria - prática concreto; em outras palavras, como destaca Fleuri (2006), ao passo que são promovidas a construção da identidade social e o reconhecimento das diferenças entre as culturas, também se procura manter uma relação crítica e solidária entre elas.

Outrossim, nosso maior desafio é, sem dúvida, o reconhecimento da existência de outras visões de mundo considerando a validade de outros conhecimentos, de outras formas de construir conhecimentos, isto é, o reconhecimento mútuo de todas as culturas sem hierarquização.

Nessa direção, o Curso é, ainda, "específico e diferenciado", porque procura atender às necessidades e aos interesses de cada povo indígena que busca o ensino superior com vistas a articular a formação de seus professores com o Projeto Político-Pedagógico de suas escolas, discutindo, em especial, a implantação do $6^{\mathrm{a}}$ ao $9^{\mathrm{a}}$ ano do Ensino Fundamental e o futuro Ensino Médio nas aldeias.

Portanto, a proposta de criação na UFAM de um Curso de Licenciatura em Formação de Professores Indígenas é uma iniciativa que atende à perspectiva da inclusão social, no contexto da efetivação de novas políticas públicas que sejam alterativas, em outras palavras, aquelas que tanto levam em conta a alteridade, como têm o poder de mudar a realidade. Essas políticas devem respeitar profundamente a diversidade sócio-político-cultural dos povos e convergir para a nova prerrogativa constitucional do "direito à diferença" e do "direito à cidadania plural", dentro do estatuto maior da autonomia, ao valorizar e apoiar as especificidades, ter o poder de alterar a situação de desigualdade social, possibilitando igualdade de oportunidades.

Por isso, a Licenciatura em Formação de Professores Indígenas/UFAM, tem, como sua proposta, formar - no mesmo curso - licenciados em três grandes áreas, a saber: 1) Ciências Humanas e Sociais; 2) Ciências Exatas e Biológicas e 3) Letras e Artes - assumindo, como princípio 
e exigência, a perspectiva e atitude interdisciplinar em virtude da inter-relação entre as diferentes áreas do conhecimento que estarão presentes no Curso.

Lembramos que, quando se fala em acesso ao ensino superior, é relevante apontar que existem outros "desdobramentos" tão ou mais importantes, como a problemática da permanência e da consequente saída exitosa. Ou seja, é preciso pensar em condições concretas que possibilitem novos percursos acadêmicos.

Tais desdobramentos têm se constituído em novos desafios para ambos - UFAM, professores e estudantes indígenas. $\mathrm{O}$ enfrentamento requer uma política pública que garanta e respalde esta iniciativa de ação afirmativa de caráter intercultural - em especial quanto ao seu financiamento e a ampliação dos recursos humanos (docentes e técnicos).

Há de se destacar, nesse contexto de interculturalidade, como destaca o PPP (Brasil/UFAM, 2012), que a presença indígena na academia tem propiciado o intercâmbio entre diferentes saberes, experiências e conhecimentos, constituindo-se em importante oportunidade de debate com outros referenciais e paradigmas. Assim, os dois lados poderão sair ganhando: os povos indígenas e a Universidade

Para se consolidarem enquanto Educação Escolar Indígena, diferenciada e de qualidade, as escolas indígenas necessitam que, em seu povo, sejam formados professores qualificados, com formação em nível superior, de modo a atender as demandas da Educação Básica em suas aldeias e comunidades.

Nesse sentindo, o Curso tenta propiciar espaços por meio do ensino, da pesquisa e da extensão com eixos norteadores - possibilitando o diálogo dos saberes de cada povo com os saberes das diferentes áreas do currículo, numa perspectiva interdisciplinar, de modo tal que os professores possam desenvolver atividades voltadas para a busca de possíveis soluções dos problemas enfrentados pela comunidade indígena, transformando-o de maneira significativa. Assim, efetiva-se o compromisso social que tem a Universidade com a maioria da população, sobretudo do interior do Estado.

Logo, é nesse contexto de diversidade cultural e linguística, de anseios dos povos indígenas pela formação superior de seus professores e estudantes, que estão inseridas nossas atividades de ensino, de pesquisa e de extensão, desenvolvidas e em andamento, na perspectiva interdisciplinar, intercultural e intracultural da Educação Matemática, a serem descritas a próxima seção; sendo estas também partes dos desafios que ora enfrentamos, no desenvolvimento do ensino e da aprendizagem das matemáticas.

\section{Os Desafios de uma Formação Interdisciplinar, Intercultural e Intracultural na Perspectiva da Educação Matemática}

Como destacado na seção anterior, para interagirmos com os indígenas precisamos, antes de tudo, acolher para sermos acolhidos, integrar-nos para sentir-nos integrados. Essa compreensão deve permear todas as nossas atividades, principalmente ao planejar e ao desenvolver as práticas matemáticas. É preciso considerar também que esses estudantes já possuem seus etnoconhecimentos, quer sejam os linguísticos, os culturais, os sociais, os econômicos, dentre tantos outros, e almejam compreender, entender e aprender a Matemática do não indígena para lidar com as diversas relações que são estabelecidas por meio de números e principalmente de suas práticas sociais. 
Esses quereres nos lembram o diálogo entre Sebastiani Ferreira $(2018)^{2}$ e um indígena, que destacou: “o 'branco' usa a Matemática do 'não indígena' como uma 'arma', precisamos também ter essa 'arma', para podermos lutar de igual a igual com eles". Na sequência, o autor reflete: "Essa consciência política, que o indígena me transmitiu, convenceu-me ainda mais da importância que tem para eles possuírem esse bem da humanidade: a Ciência Matemática".

Nesse sentido, projetamos nossas ações de ensino e de aprendizagem da 'Ciência Matemática', para a formação inicial de professores na perspectiva interdisciplinar e intercultural pautada no compartilhar dos saberes originários indígenas e dos conhecimentos matemáticos imbricados nesses saberes.

Nossa metodologia de ensino parte do propósito de estabelecer o diálogo formativo entre os estudantes indígenas e os professores-formadores-pesquisadores-orientadores, para que em um primeiro momento estes últimos, quando possível, possam verificar as potencialidades do ensino de Matemática numa perspectiva interdisciplinar e intercultural, visto que esses estudantes vivem, em seu cotidiano comunitário, uma diversidade de saberes originários e, nos contextos externos, uma variedade de conhecimentos socioculturais, em especial, por estarem localizados na região amazônica do Alto Solimões, numa tríplice fronteira - Brasil, Peru e Colômbia. Esse contexto intercultural promove novos olhares, vivências, experiências e aprendizagens cotidianas que certamente causam reflexos nas linguagens matemáticas em sala de aula.

No segundo momento, após compreendermos as suas necessidades de aprender, de conhecer e de praticar a Matemática Acadêmica, a Matemática Escolar e a Matemática do Cotidiano, respectivamente, -segundo David; Moreira \& Thomas (2013), a primeira se caracteriza ao ser associada à constituição de um corpo científico de conhecimentos, conforme produzido pelos matemáticos profissionais; a segunda, entendida como um conjunto de práticas e saberes associados ao desenvolvimento do processo de Educação Escolar em Matemática; e, a terceira, composta por um conjunto de ideias, de saberes e de práticas, caracterizando seu uso em situações do cotidiano, fora da escola - para entenderem o mundo dos números dos não indígenas, temos o cuidado e o respeito em proceder valorizando os saberes matemáticos do cotidiano indígena, que estão intrinsecamente relacionados às suas demandas, principalmente no desenvolvimento de atividades e de tarefas referentes às suas subsistências.

Destas propositivas, trazemos dois pontos para a discussão e reflexão a partir da Educação Matemática: o primeiro, refere-se a algumas compreensões sobre o ensino e a aprendizagem de Matemática interdisciplinar e intercultural, (visto que a disciplina de Fundamentos de Matemática Elementar II, ministrada aos estudantes indígenas ocorreu no núcleo comum do Curso de Formação de Professores Indígenas, sendo consideradas, nesse processo formativo, as atuações docentes com o ensino de Matemática, com destaque aos segmentos escolares Multisseriados - nos Anos Inicias do Ensino Fundamental I, Ensino Fundamental II e Médio), e o segundo converge para as aprendizagens interdisciplinares, pois nesse momento do Curso, os estudantes ainda não optam pela área de atuação futura como professores em suas comunidades/aldeias. Isso só ocorre na "etapa de formação específica" (Brasil/PPP/UFAM, 2012), na qual o Curso é subdividido em três áreas do conhecimento: "Letras e Arte"; "Ciências Humanas e Sociais" e "Ciências Exatas e Biológicas".

Para fomentarmos em sala de aula outras práticas de ensinar e de aprender as matemáticas num contexto de diversidade sociocultural e ao mesmo tempo singular e plural, partimos então, de uma compreensão do conhecimento escolar compartilhado, ainda de forma disciplinar, como sendo:

Um arranjo, organizado segundo critérios internos à própria disciplina, de um aglomerado de modos de explicar (saber), de manejar (fazer), de refletir, de prever, e dos conceitos e normas associados a esses modos. [em outras palavras...] Arranjar o

${ }_{2}^{2}$ Fragmentos extraídos da $4^{\text {a }}$ capa de Melo \& Bacury (2018). 
conhecimento numa "ordem" disciplinar é algo que deixa de lado outras manifestações de conhecimento, justamente aquelas que não obedecem a essas normas. (D'Ambrosio, 1993, p. 82)

Todavia, vale ressaltar que, em se tratando dos processos de ensinar e de aprender a Matemática, quer seja em espaços escolares, acadêmicos e/ou da educação básica, quer seja em espaços localizados em centros urbanos centrais e/ou periféricos e os rurais (indígenas e/ou campo), ainda é notório o uso das práticas docentes disciplinares, visto que mobilizar ações de aprendizagens em sala de aula de forma interconectada a outros conhecimentos disciplinares requer quebrar e romper com os "cclubes" disciplinares, que surgem quando se obedece a critérios fixados a priori e permite-se, naturalmente, o acesso somente a certos conhecimentos "aceitos no clube"” (D’Ambrosio, 2016, p. 53).

Romper com esses "clubes disciplinares” é um dos desafios da Educação Matemática, que objetiva o diálogo educativo e formativo de forma global, tecnológica e ética, de modo a interagir com os estudantes indígenas na "produção e crítica de novos conhecimentos" (D'Ambrosio, 1996, p. 80).

Logo, considerando a aquisição e o compartilhar dialógico entre pessoas que possuem compreensões diversas sobre o mesmo conhecimento, disciplinar ou não, entendemos isso como uma das possibilidades de quebrar o paradigma dos "clubes disciplinares" e transformar as práticas de ensinar e de aprender em momentos interdisciplinares, sem subjugar as percepções, ao mesmo tempo que se busca interconectá-las.

Nessa perspectiva de interação e troca de conhecimentos em distintos espaços de aprendizagens, há de se reconhecer a complexidade dos fenômenos, que resistiam aos métodos das várias disciplinas isoladamente, com destaque para a Matemática Acadêmica.

Portanto, é nesse bojo de discussões, que D’Ambrosio (2011, p. 9), considera que na interdisciplinaridade "não apenas se transferem e se combinam resultados de algumas disciplinas, mas também se combinam métodos de várias disciplinas e, consequentemente, identificam-se novos objetos de estudo. Chega-se, assim, a possibilidades de explicações de inúmeros fenômenos e de realizações notáveis". Entendemos que nesse processo não há uma hierarquia entre as disciplinas e todas devem ter sua identidade reconhecida e respeitada.

A busca constante por métodos de ensinar e de aprender Matemática interconectada a outras áreas do conhecimento escolar têm contribuído com o redimensionar de muitos objetos de pesquisa e ações de ensino, provocando, assim, novas práticas docentes em sala de aula. Essas novas práticas são pautadas em procedimentos didáticos, pedagógicos e metodológicos ancorados em diferentes bases epistemológicas das ciências escolares e acadêmicas, convergindo para a transdisciplinaridade, a qual busca, dentre outros aspectos do comportamento humano, o respeito, a solidariedade e a cooperação, ou seja, "a transdisciplinaridade vai além das limitações impostas pelos métodos e objetos de estudo das disciplinas e da interdisciplinaridade" (D’Ambrosio, 2016, p. 58).

Assim, temos que o ensino de Matemática em contexto de diversidade sociocultural, em especial o indígena, possibilita a mobilização não só do agregar de várias disciplinas, mas a reflexão sobre os objetos de estudos e pesquisas, de modo a potencializar novas ações de aprendizagens das matemáticas. Dessa forma, as ações são compartilhadas por meio do respeito, da solidariedade e da cooperação entre os que ensinam na prática do saber fazer e os que aprendem no silêncio e no observar, sendo essas aprendizagens potencializadas por meio de conhecimentos escolares advindos de trocas, de interações, do compartilhamento de experiências e de vivências interculturais e intraculturais.

Em se tratado dos contextos comunitários, os povos indígenas da Região do Alto Solimões/AM vivem as mais diferentes realidades socioculturais, ou seja, eles de fato constituem um 
multiculturalismo étnico e linguístico de manifestações culturais. Assim ocorrem as interações interculturais e intraculturais compreendidas como:

a geração de novas formas culturais, identificadas com a modernidade. Ainda denominadas pelas tensões emocionais, as relações entre indivíduos de uma mesma cultura (intraculturais) e, sobretudo, as relações entre indivíduos de culturas distintas (interculturais) representam o potencial criativo da espécie. [... é] na diversidade cultural [que] que reside o potencial criativo da humanidade. (D’Ambrosio, 2004, p. 42)

Essas compreensões nos permitem pensar que é possível enfrentarmos os desafios propostos pelos sistemas de ensinar e de aprender a Matemática numa perspectiva disciplinar a partir de uma formação interdisciplinar, intercultural e intracultural pautada na Educação Matemática, desde que esse processo educativo e formativo possa mobilizar em sala de aula "outras aprendizagens matemáticas - como as Matemáticas do Cotidiano Escolar Indígena - [...] acrescidas no diálogo entre a formação, a atuação futura e as práticas nas escolas de suas comunidades" (Bacury \& Melo, 2018, p. 159).

Assim, as matemáticas dos povos indígenas e a Matemática Escolar constituem novos balizadores intraculturais e interculturais, a partir de uma reflexão crítica a respeito do ensino e da aprendizagem da Matemática nos processos de formação dos estudantes indígenas e nas escolas, ao valorizar os distintos conhecimentos advindos daqueles que produzem e orientam suas vidas entre saberes e fazeres próprios, mas que também necessitam adquirir outros conhecimentos, como elementos essenciais ao projetarem novos olhares para a educação escolar indígena e para as suas sobrevivências físicas e culturais, em contextos de diversidade sociocultural e linguística, como ocorre com os povos indígenas da região do Alto Solimões/AM.

$\mathrm{Na}$ perspectiva de provocarmos algumas transformações nos processos de ensinar e de aprender as matemáticas dos estudantes indígenas dessa turma e também em nós próprios, professores-formadores-pesquisadores-orientadores, com vista à problematização de atividades e à produção de novos conhecimentos compartilhados, adentramos ao contexto cultural e formativo desses estudantes, para que pudéssemos conhecer suas realidades socioculturais, a fim de despertar motivações e interesses durante o desenvolvimento da disciplina de Fundamentos de Matemática Elementar II, o qual passaremos a descrever.

\section{Trilhando um Caminho Investigativo no Cotidiano Comunitário das Aldeias Indígenas do Alto Solimões/AM}

A nossa procura por conhecer as interconexões entre a Matemática Acadêmica, a Escolar e do Cotidiano, como propõem David; Moreira \& Thomas (2013), e a do Cotidiano Escolar Indígena, como indicam Bacury \& Melo (2018), deu-se por meio da pesquisa realizada no âmbito do Curso de Licenciatura em Formação de Professores Indígenas/UFAM/Câmpus de Benjamin Constant, na região do Alto Solimões/AM, com os estudantes indígenas, no desenvolvimento da disciplina de Fundamentos de Matemática Elementar II.

A realização da pesquisa integrou um conjunto de ações e de metas propositivas para o ensino e a aprendizagem das 'Matemáticas do Cotidiano Escolar Indígena' a partir de práticas, de saberes e de fazeres dos cotidianos indígenas, que, no desenvolvimento diário de seus "empreendimentos conjuntos e repertório compartilhado em comunidades de prática" (Wenger, 2001), expressam e representam elementos conceituais da Matemática escolar.

Para tanto, no desenvolvimento da disciplina, fez-se uma investigação de abordagem qualitativa, a partir da pesquisa de natureza etnográfica pautada na participação para observar e do 
observar para participar, como indica Guber (2012), na qual as informações recolhidas foram provenientes das anotações/notas/registros de sala de aula dos "percursos formativos" (Bacury, 2017), da visita técnica e pedagógica à comunidade indígena, das conversas informais com os estudantes e entre os professores-formadores-pesquisadores-orientadores, das discussões e reflexões acerca dos fatos ocorridos, que muitas vezes não foram registrados em cadernos, mas se fizeram presentes nos registros mentais e problematizados em atividades em sala de aula.

Antes de adentrarmos o contexto comunitário da comunidade/aldeia Ticuna-Bom Caminho, localizada no município de Benjamin Constant/AM, optamos em um primeiro momento por conhecer o processo de formação dos estudantes e dos professores indígenas da região do Alto Solimões/AM, a partir de suas vivências e experiências na disciplina de Fundamentos de Matemática Elementar II. Recorremos às suas histórias de vida, aqui denominadas como 'percursos formativos', a fim de desvelar suas motivações e seus interesses, de modo a buscarmos possível(eis) resposta(s) para nossa questão de pesquisa, assim como atingir o objetivo proposto neste artigo.

Para tanto, buscamos captar, por meio desse instrumento, as informações, as impressões, as percepções e os episódios junto aos estudantes e professores indígenas. Essa recolha ocorreu durante a realização da disciplina de Fundamentos de Matemática Elementar $\mathrm{II}^{3}$, para fins de discussão, reflexão e encaminhamento da pesquisa etnográfica junto à comunidade indígena Bom Caminho, do povo Ticuna, a qual, dentre outras questões, balizou e problematizou as atividades interdisciplinares, intraculturais e interculturais no estudo de alguns conceitos no campo da Geometria Plana.

Dada a carga horária extensa da disciplina de Fundamentos de Matemática Elementar II, ministrada de segunda-feira a sábado, nos períodos matutino e vespertino, numa carga horária de 8h/dia -, optamos por realizar a visita de campo à comunidade indígena Bom Caminho no domingo, como segundo momento do trabalho/pesquisa, empreendido em nossas atividades docentes.

Assim, organizamos nossa visita juntamente com mais 3 estudantes, sendo um residente na referida comunidade, outro da comunidade Ourique e o terceiro na comunidade Umariaçu II, ambas localizadas em terras indígenas Ticuna, no município de Tabatinga/AM.

Ao chegarmos à comunidade de Bom Caminho, fomos apresentados à família do estudante $\mathrm{e}$ colaborador desta pesquisa.

Ao apresentar sua comunidade, destacou que ela possui uma população de aproximadamente 1000 pessoas, entre recém-nascidos, crianças, jovens, adultos e anciãos. Quanto à infraestrutura, a comunidade possui uma escola pública que atende aos estudantes; um posto de atendimento à saúde; as casas estão dispostas ao longo dos espaços físicos da comunidade, que está localizada às margens do rio Solimões, de onde provém parte da segurança alimentar dos Ticuna - o peixe.

A comunidade também mantém a sustentabilidade e renda financeira por meio de vencimentos provenientes de ocupações trabalhistas em cargos públicos, como de professores, de coordenadores e de diretores escolares, de vigia noturno, de merendeira, de auxiliar de limpeza, de agentes de saúde, bem como da renda dos benefícios previdenciários (aposentadoria) e do Bolsa Família. Além destes, há os subsídios advindos da venda de peixes, da produção da agricultura familiar, da fabricação de canoas, de redes de pesca (malhadeiras) e, em especial, da confecção de artesanatos pelas mulheres Ticuna.

Ao conhecermos o contexto sociocultural dessa comunidade, chamou-nos a atenção a habilidade e o cuidado das Mulheres Artesãs Ticuna ao produzirem seus artesanatos, conforme

${ }^{3}$ As histórias de vidas e de formação dos estudantes e professores indígenas, regularmente matriculados no Curso de Licenciatura em Formação de Professores Indígenas/UFAM/Câmpus de Benjamin Constant/AM, serão motivo de discussões e de reflexões em escritas futuras. 
ilustrado no mosaico da Figura 1. Esse aprendizado é adquirido por meio da oralidade, da observação e do fazer, a partir da arte de trançados das fibras extraídas das palmeiras do arumã. Prática esta que dá vida, sentido e significado aos elementos sociais e culturais materializados nos diversos artesanatos.
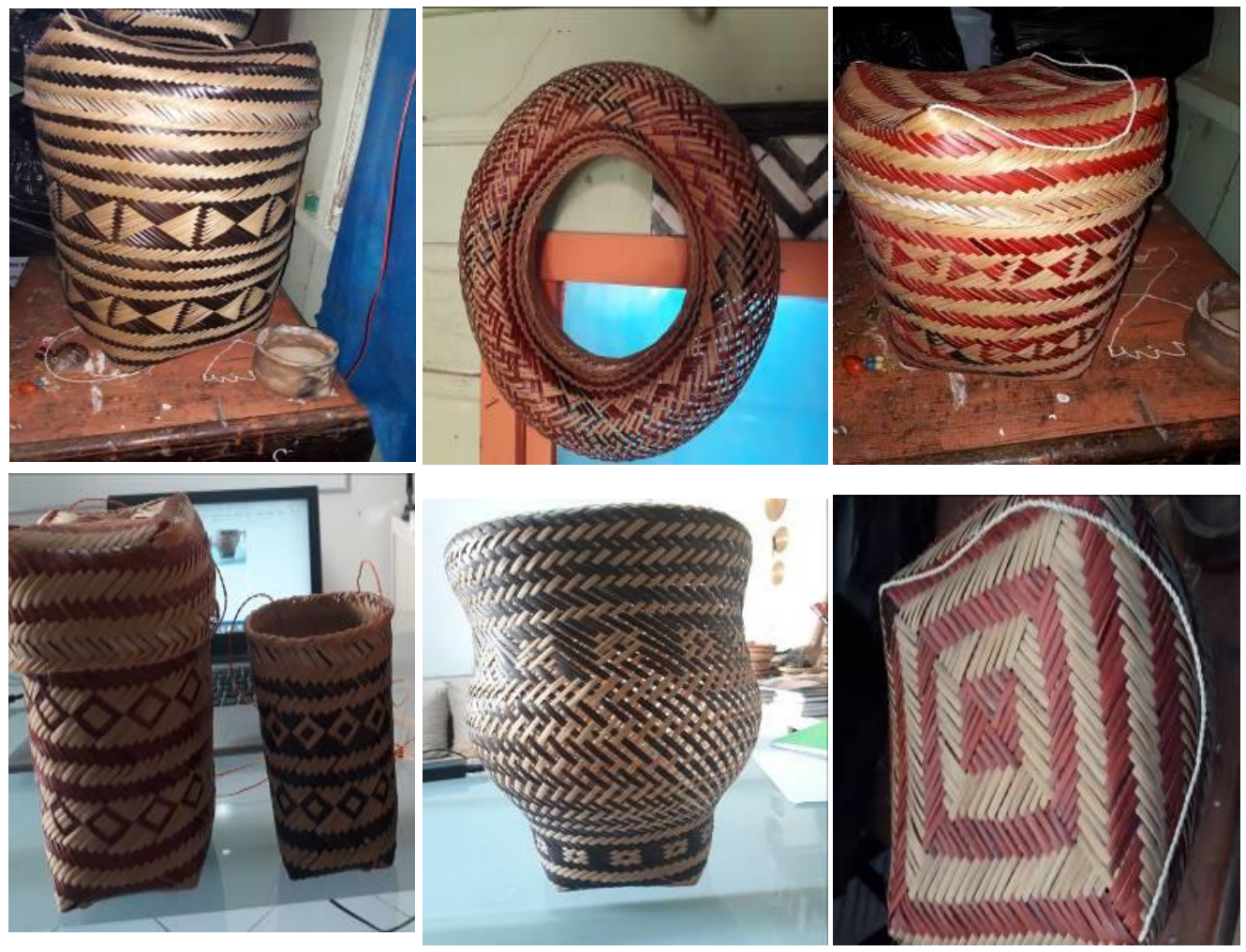

Figura 1. Produção de Artesanatos Ticuna

Fonte: Registro dos pesquisadores

Esses artesanatos Ticuna transmitem múltiplas informações, leituras, olhares e modos próprios de conceber e viver a vida a partir da natureza, da ecologia, da economia, dos sistemas de troca, das relações de parentesco, assim como potencial cognitivo e simbólico daqueles que os constroem, além disso, são veículos de ideias, de conhecimentos e de saberes. Ademais, "têm um caráter fortemente artístico e matemático. Embora os aspectos matemáticos dessa atividade cultural tradicional não tenham, ou quase não tenham sido reconhecidos pela 'Academia', isso não os tornam menos matemáticos.” (Gerdes, 2011, p. 07)

Essa vivência e o novo conhecimento ao qual fomos submetidos suscitou a metodologia de ensino adotada no intuito de fomentar o diálogo e, posteriormente, abordar os elementos conceituais da Matemática presentes nos artesanatos/cestarias produzidas pelas mulheres Ticuna, com destaque aos conceitos de Geometria Plana.

Passaremos a discutir esses pressupostos na próxima seção, a partir de um sistema compartilhado de ensinar e de aprender a Matemática Escolar por meio de atividades interdisciplinares, mobilizadas pelas Matemáticas do Cotidiano Escolar Indígena.

\section{Ensinando e Aprendendo as Matemáticas na Formação de Professores Indígenas do Alto Solimões/AM}

Como destacado anteriormente, as atividades propostas para a disciplina de Fundamentos de Matemática Elementar II têm uma carga horária extensa de conteúdos a serem ensinados e 
aprendidos na perspectiva disciplinar, interdisciplinar e intercultural. Essas atividades tornam-se exaustivas à medida que consideramos o desenvolvimento pedagógico, didático e os desafios inerentes ao processo de ensino e de aprendizagem da Matemática nas escolas indígenas, de modo a darmos as possibilidades que correspondam às expectativas dos professores indígenas em formação inicial, de aprender a Matemática e posteriormente ensinar aos seus futuros estudantes.

Assim, buscamos diversificar as metodologias de ensino face aos conteúdos propostos para serem ministrados na referida disciplina, tendo em vista as aprendizagens matemáticas dos estudantes e professores indígenas; de modo a desenvolvermos, juntamente com todos os envolvidos, distintas abordagens do conhecimento matemático na sala de aula, relacionando-as aos contextos socioculturais e linguísticos dos povos indígenas do Alto Solimões/AM.

Dentre os vários conteúdos propostos e desenvolvidos junto aos estudantes e professores indígenas, trazemos para a discussão e reflexão algumas atividades, abordando o conceito dos Polígonos Regulares. Para tanto, recorremos a uma 'videoformação' desenvolvida por um dos autores deste artigo - o professor Domingos Anselmo Moura da Silva ${ }^{4}$, do Departamento de Matemática do Instituto de Ciências Exatas (ICE)/UFAM. Esse recurso tomou como base a criação de um Material Concreto, nesse sentido, dadas as circunstâncias e dificuldades enfrentadas para a sua confecção e levando em consideração o conteúdo matemático a ser trabalhado, optamos pelo uso do Geoplano ${ }^{5}$, conforme ilustrado no mosaico da Figura 2, a seguir.
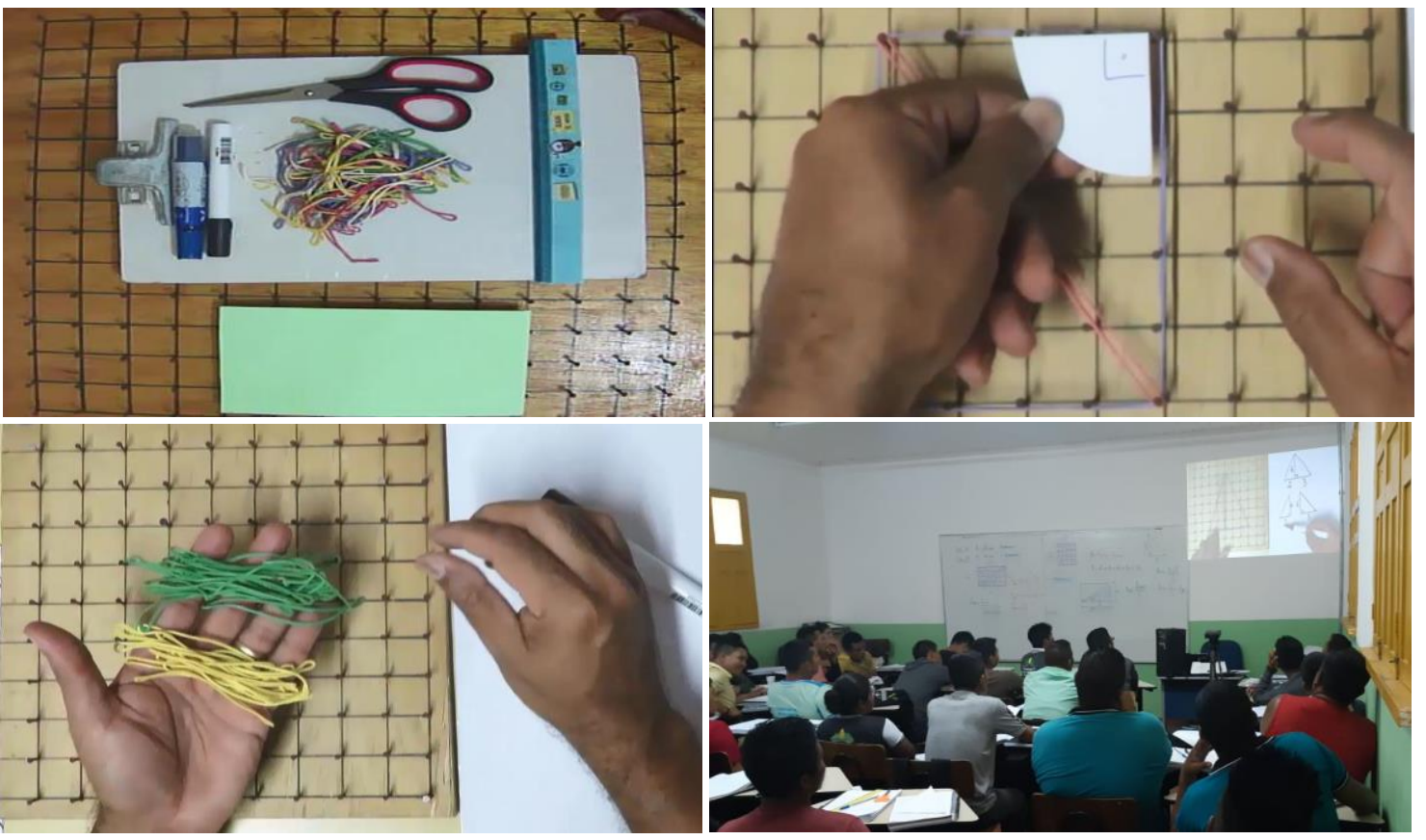

Figura 2. Construção e Manuseio do Geoplano

Fonte: Registro dos pesquisadores

\footnotetext{
${ }^{4}$ Esse foi o primeiro professor do Curso de Licenciatura em Formação de Professores Indígenas/UFAM a ministrar as disciplinas de Matemática.

${ }_{5}^{5}$ Os primeiros trabalhos publicados sobre o Geoplano ocorrem em 1961, de autoria do Dr. Caleb Gattegno. Nos dias atuais, o Goplano tem larga utilização como ferramenta para o ensino e aprendizado da Geometria Plana, das Frações, da Matemática Financeira, dentre outros.
} 
Nessa videoformação, o professor Domingos Anselmo não só apresenta os materiais e ferramentas para confeccionar o Geoplano, tais como: martelo, ligas de borracha, pregos, tábua de madeira, dentre outros, mas, também inicia os processos para o conhecimento de alguns Polígonos Regulares, como o quadrado, o retângulo, o triângulo, o trapézio, o hexágono, o pentágono, o paralelogramo, o losango e outros polígonos, considerando as suas propriedades conceituais, quanto aos ângulos internos e lados.

No sentido de ampliar o processo e a relação teoria - prática - concreto, também levando em consideração a falta de materiais e ferramentas para a construção do Geoplano, fizemos uso da criatividade, desenvolvendo esse Material Concreto na forma de impressão em uma folha de papel tamanho A4, em duas versões: a malha e o conjunto de pontos. A partir da construção desse material, os estudantes começaram a desenvolver as atividades, fatos esses ilustrados no mosaico da Figura 3, a seguir.

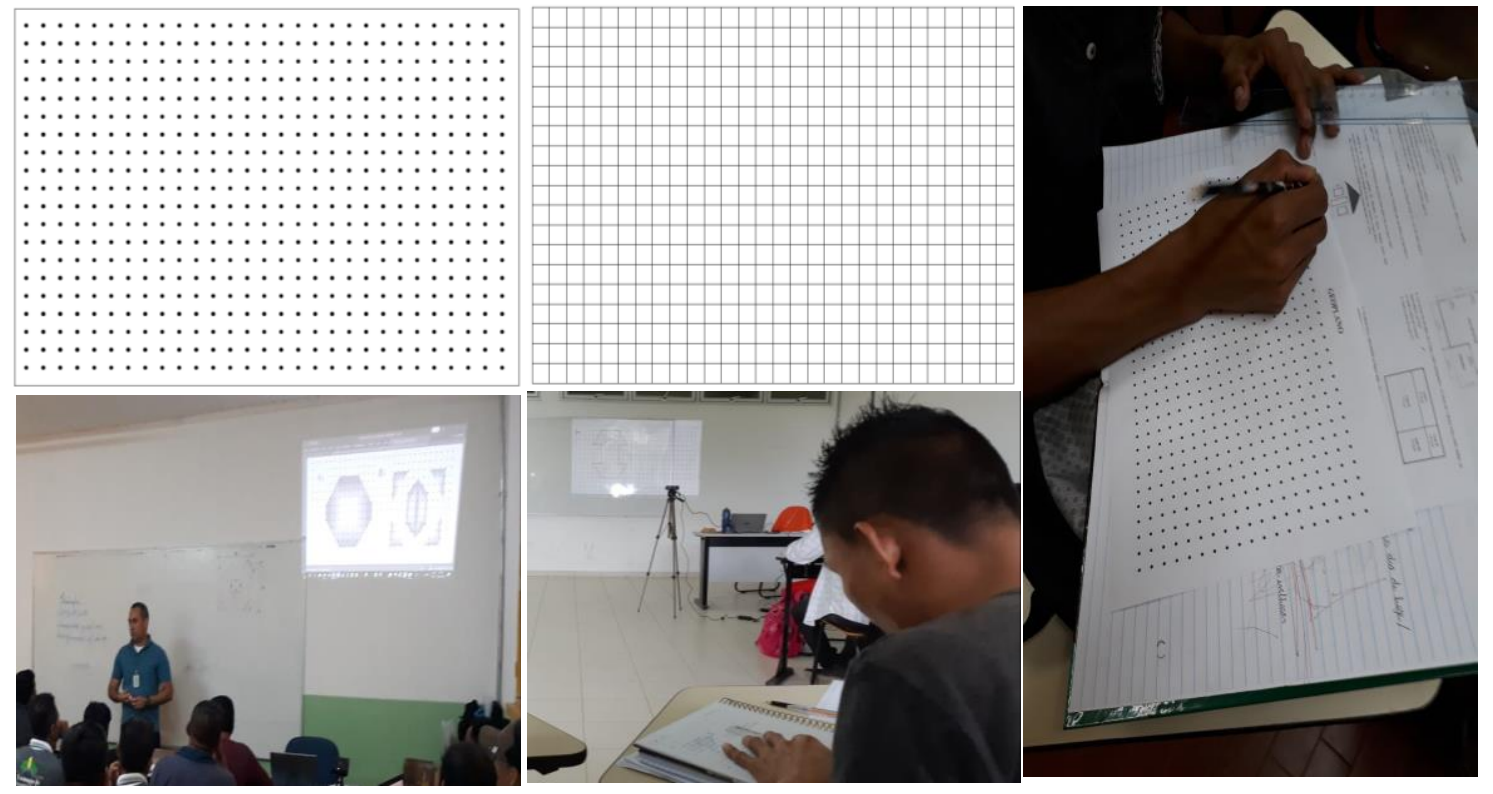

Figura 3. Atividades com o Geoplano em Malha e conjunto de pontos Fonte: Registro dos pesquisadores

Das compreensões iniciais dos estudantes, passamos a discutir, num primeiro momento, sobre como calcular a área de Polígonos Regulares sem o uso de expressões. Tomamos como princípio a ideia de unidade de área, em seguida, abordamos o cálculo das áreas do Retângulo e do Quadrado. A partir disso, no segundo momento, mostramos que a partir do cálculo da área do Retângulo é possível calcular a área de qualquer Triângulo Retângulo. E assim, ampliando esses conceitos, apresentamos que, com o conhecimento prévio dessas áreas, pode-se calcular a área de qualquer polígono regular, conforme ilustrado no mosaico da Figura 04, a seguir. 

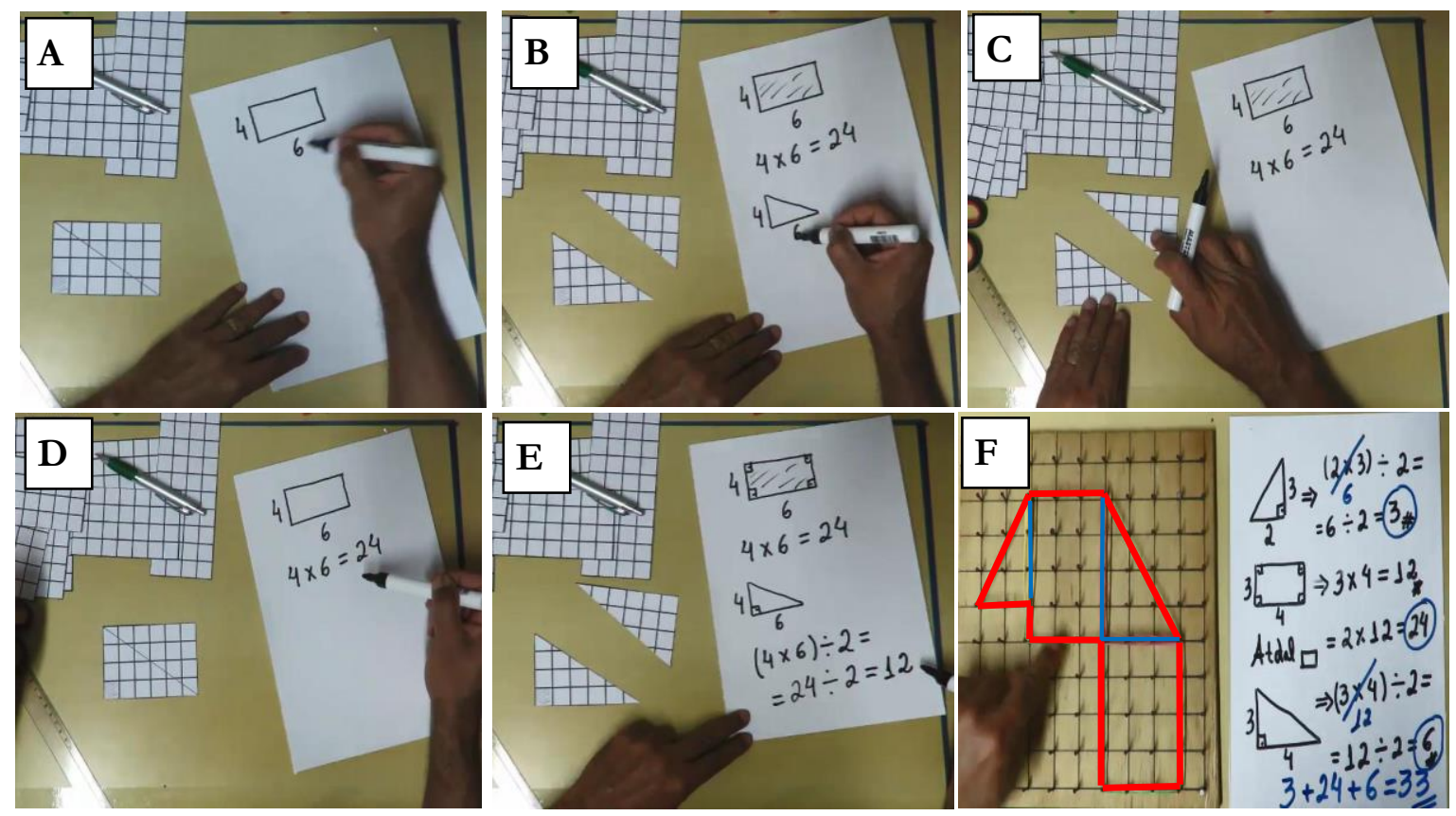

Figura 4. Cálculo de áreas de Polígonos Regulares por meio do Geoplano Fonte: Registro dos pesquisadores

As Figuras 4A e 4B apresentam o desenvolvimento de cálculo da área de um Retângulo qualquer com mediadas $4 \mathrm{u}$ (unidades) e $6 \mathrm{u}$ (unidades), respectivamente, no qual encontramos a área de 24 u.a (unidade de área).

Todavia, é chamada a atenção, na Figura 4C, quando dividimos o Retângulo em dois Triângulos Retângulos congruentes. Nesse momento, conforme a Figura 4D, temos um Triângulo Retângulo com os lados medindo 4 u e 6 u, respectivamente.

Portanto, é indagado aos estudantes que relação há entre esses Polígonos, de modo que eles verifiquem, por meio da manipulação, que a área do Triângulo é dada pela metade da área do Retângulo, com efeito, obtendo o resultado igual a 12 u.a, conforme a Figura 4E.

A partir dessas percepções, considerando a Figura 4F, foi apresentada outra atividade envolvendo o cálculo de área. Foi dado um Polígono qualquer - determinado por uma poligonal fechada na cor vermelha. Nessa prática, é solicitado aos discentes que calculem a área desse Polígono.

A ideia é realizar o desenvolvimento desse cálculo, por meio das partes - dividindo a figura em outras já conhecidas como Retângulos e Triângulos Retângulos - , até chegar ao todo; em outras palavras, encontrar a área de todo o Polígono apresentado a partir da soma entre as áreas formadas por Retângulos e Triângulos Retângulos, de modo a encontrar como solução o resultado igual a 33 u.a.

Fazendo uma Relação com os conhecimentos científicos desenvolvidos no âmbito da Análise Matemática, essa atividade envolve os conhecimentos de Integral (operações de encontrar “somas"), cuja ideia foi desenvolvida por Newton (1643-1727) e Leibniz (1646-1716). Entretanto, foi Riemann (1826-1866) que apresentou esses conhecimentos de maneira mais formal com base em sua tese de doutorado defendida nos anos de 1851, abordando a teoria das funções complexas, de onde emerge o conceito de Superfície de Riemann.

No desenvolvimento desses estudos, o cálculo da área $\mathbf{S}$, com base na Figura 5, é delimitado por uma função $\mathrm{f}(\mathrm{x})$ contínua e positiva num intervalo $[\mathrm{a}, \mathrm{b}] \in \mathfrak{R}$ (conjunto do Números Reais) e o 
eixo x, no mesmo intervalo. Para encontrar o resultado, basta determinar o valor da soma (\$) entre as subáreas $\Delta_{\mathrm{x}} \cdot \mathrm{F}\left(\mathrm{x}_{\mathrm{i}}\right)$ no intervalo [a, b]:

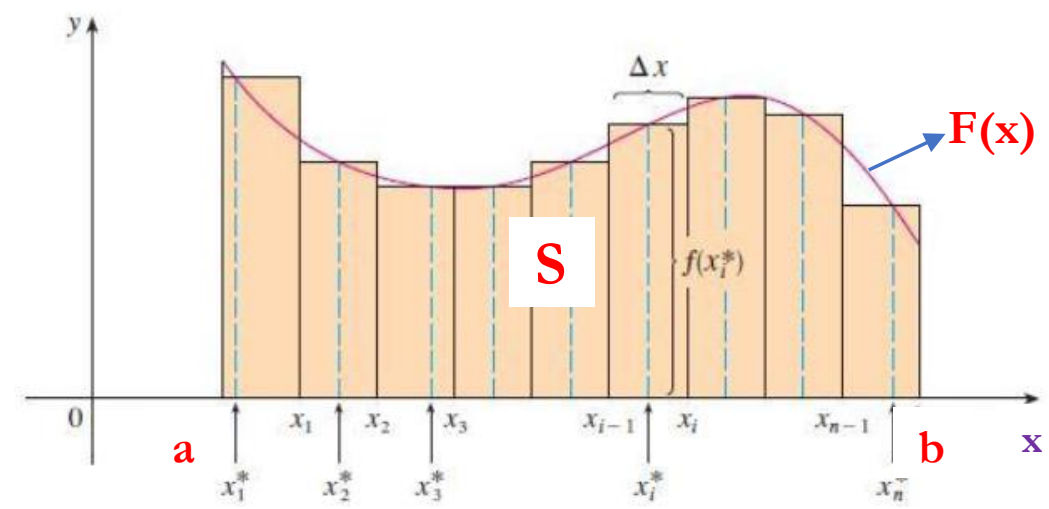

Figura 5. Cálculo a Área áreas $\mathbf{S}$

Fonte: Desenvolvido pelos pesquisadores

Em escrita da Matemática Formal, temos:

$$
S=\int_{a}^{b} F(x) d x
$$

Guidorizzi (2007) ressalta que dos estudos do Cálculo Diferencial e Integral, com destaque para a Integral de Riemann, decorrem o Teorema Fundamental do Cálculo que, além do cálculo de área, tem utilização para o cálculo de volume para os sólidos de revolução, aceleração, velocidade, dentre outros. Essas colocações só ressaltam a importância de se relacionar a Matemática Acadêmica com a Matemática Escolar e com a Matemática do Cotidiano, na acepção de David; Moreira \& Thomas (2013); e com a Matemática do Cotidiano Escolar Indígena, como propõem Bacury \& Melo (2018), nos contextos comunitários indígenas.

No sentido de ampliar as discussões e compreensões sobre o estudo da Geometria Plana e o cálculo de áreas, passamos a discutir e a solicitar que eles encontrassem soluções para algumas situações-problemas envolvendo também as Medidas de Superfícies, conforme descrito a seguir:

Um terreno foi dividido em 4 lotes, todos retangulares. As áreas de 3 desses lotes estão dadas, na figura ${ }^{6}$ ao lado, em $\mathrm{Km}^{2}$. Pergunta-se:

a) Qual é a área do Terreno?

b) Qual é a área do Lote IV em $\mathrm{m}^{2}$ ?

\begin{tabular}{|c|c|}
\hline Lote I \\
$27 \mathrm{Km}^{2}$ & $\begin{array}{l}\text { Lote II } \\
18 \mathrm{Km}^{2}\end{array}$ \\
\hline Lote IV & $\begin{array}{c}\text { Lote III } \\
72 \mathrm{Km}^{2}\end{array}$ \\
& \\
\hline
\end{tabular}

${ }^{6}$ Figura elaborada pelos pesquisadores. 


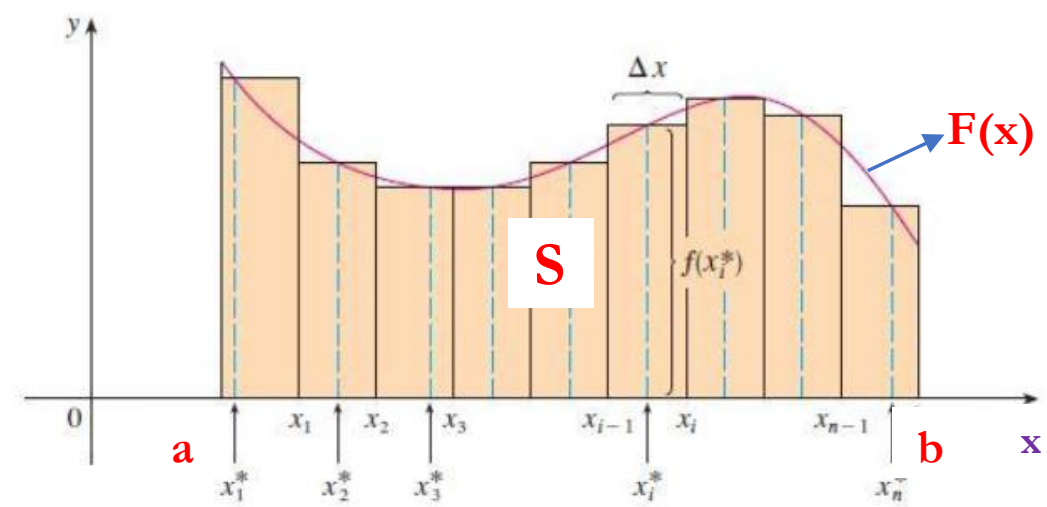

Figura 5. Cálculo a Área áreas S

Fonte: Desenvolvido pelos pesquisadores

O objetivo dessa atividade foi aproximar os estudos do cálculo de área com as compreensões e entendimentos dos estudantes quanto à questão de demarcação da área de seu território indígena, bem como no âmbito do conhecimento matemático, das relações entre as Medidas de Superfícies, como destacado na situação-problema, referente ao $\mathrm{m}^{2}$ e ao $\mathrm{Km}^{2}$. Há outra aprendizagem a ser destacada, também relacionada ao estudo do cálculo de área, a partir da seguinte situação-problema: Na planta baixa, representada na figura ${ }^{7}$ dada, sabe-se que o quarto e a área de serviço são ambos quadrados. Calcule a área da cozinha.

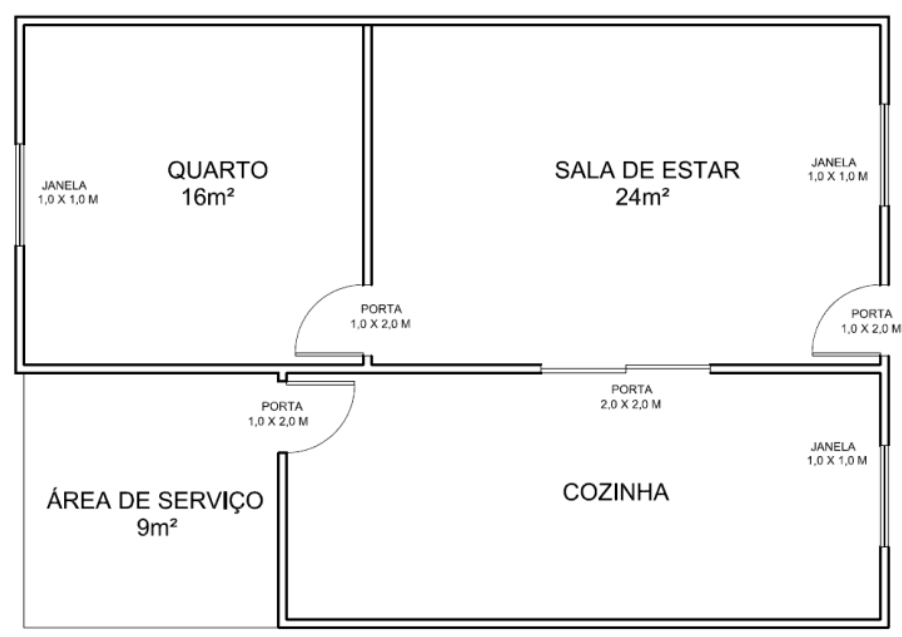

A realização dessa atividade objetivou, a partir do cálculo de área de Polígonos Regulares, abordar as aprendizagens matemáticas interdisciplinares e interculturais, visto que os estudantes indígenas também são os engenheiros, os arquitetos e os construtores de suas casas.

Nesse sentido, foram primadas as compreensões da Matemática, os entendimentos matemáticos com base no cotidiano indígena e as potencialidades de novas ações de ensino nas escolas das comunidades, mobilizando assim os processos de ensinar e de aprender em contexto de diversidade cultural e linguística - as Matemáticas do Cotidiano Escolar Indígena.

Trazemos também para a discussão outras atividades desenvolvidas com os estudantes e professores indígenas, referentes ao conteúdo de cálculo de área, agregando outros conteúdos matemáticos, como foi o caso do Perímetro de Polígonos Regulares e do Teorema de Pitágoras, conforme ilustrado na Figura 6, a seguir.

${ }^{7}$ Figura elaborada pelos pesquisadores. 

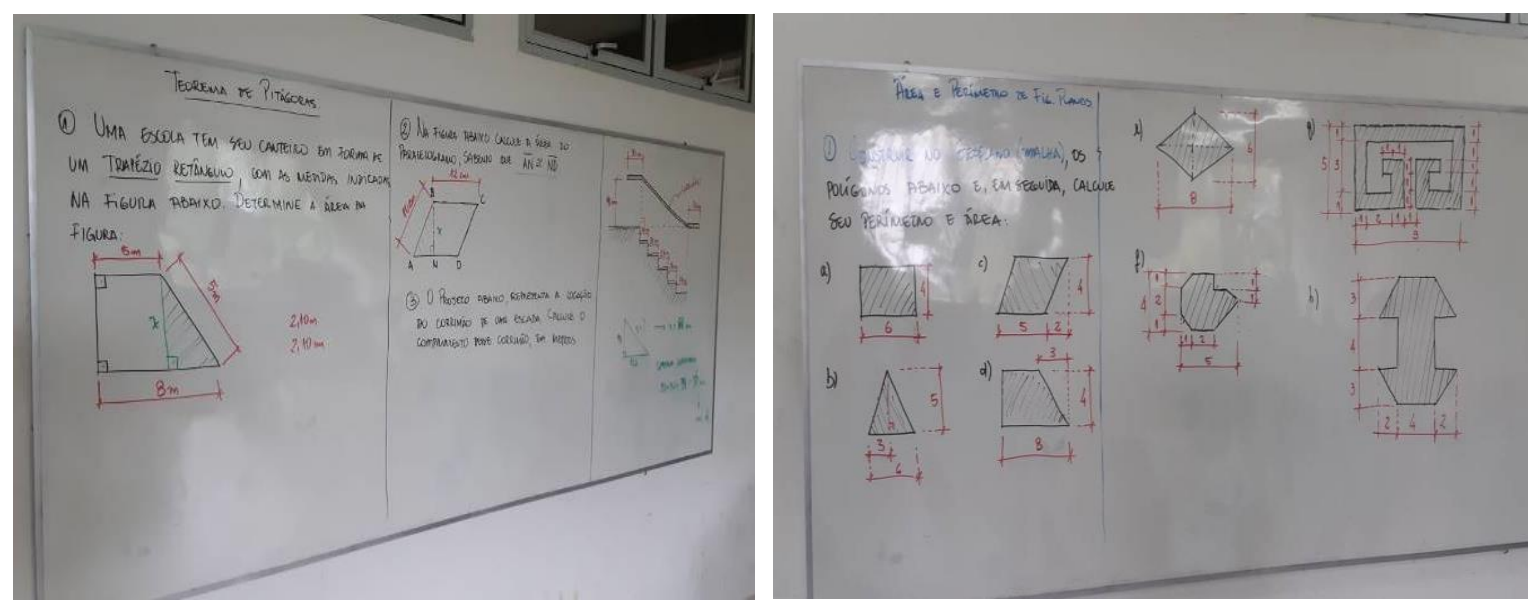

Figura 6. Atividades empreendidas em sala de aula envolvendo o cálculo de Área, Perímetro de Polígonos Regulares e o Teorema de Pitágoras

Fonte: Registros dos pesquisadores

Durante o desenvolvimento da aula e das atividades propostas, percebemos alguns obstáculos entre os estudantes e professores indígenas em formação referentes à compreensão dos termos/linguagens matemáticas empreendidas. As dificuldades estavam relacionadas ao emprego dos nomes dos polígonos e à aplicabilidade correta das equações para do cálculo de áreas de determinados Polígonos Regulares.

Isso nos fez refletir sobre o quanto é importante o saber ouvir, o observar, o silêncio, o participar, o fazer, dentre outros aspectos inerentes à relação de ensinar e de prender em contextos de diversidade linguística, como ocorre na formação de professores e estudantes indígenas, visto que, "[...] se os falantes de uma certa língua têm poder econômico e político, esta língua é geralmente respeitada, tem prestígio: sua gramática é estudada, seu vocabulário é documentado em dicionários, sua literatura é publicada" (Brasil/RCNEI, 2005, p. 117).

Nessa perspectiva e no sentido de propiciar o diálogo para além das fronteiras acadêmicas entre os que ensinam (professores-formadores-pesquisadores-orientadores) e os que aprendem (os estudantes e os professores em formação), e sim, chegar ao chão das salas de aulas das escolas indígenas, faz-se necessário compartilhar as vivências, as experiências didáticas e pedagógicas, as linguagens e línguas indígenas e matemáticas, de modo que quem ensina também aprende e quem aprende ora também ensina, por meio de repertório compartilhado (Wenger, 2001) de línguas/linguagens indígenas e matemáticas.

Ao considerarmos os processos formativos dos estudantes e professores indígenas de um modo geral, temos que desenvolver atividades que despertem todo um potencial cognitivo para que possam revitalizar ou afirmar "[...] o conhecimento que tinham desenvolvido em toda sua história [...]", já que esse conhecimento foi, de certa maneira, "subjugado [...] assim eles perderam sua língua, [...] perderam suas maneiras de fazer matemáticas" (D’ambrosio, 2018) ${ }^{8}$

Diante da realização dessas atividades balizadas pelas línguas indígenas Tícuna e Kokama e mediadas pela língua portuguesa face ao ensinar e ao aprender a Matemática, temos que os Cursos destinados à formação inicial e continuada de professores indígenas devem preparar seus estudantes

\footnotetext{
8 Palavras proferidas na Conferência do $6^{\circ}$ Congresso Internacional de Etnomatemática, ocorrido em Medellín/Colômbia, no período de 08 a 13 de jul. de 2018.
} 
para "[...] o conhecimento e a utilização da respectiva língua indígena nos processos de ensino e aprendizagem" (inciso II, art. $7^{\circ}$, Brasil/Resolução 01/2015).

Ademais, esse processo formativo, empreendido por meio de aprendizagens interculturais, permitiu aos envolvidos refletirem sobre as suas atuações em sala de aula com o ensino e a aprendizagem da Matemática, bem como a constituir novas práticas metodológicas, que resultarão em sentido e significados ao redimensionarem os processos educativos em contextos de diversidade linguística e sociocultural.

A realização dessas atividades propiciou aos envolvidos o despertar da criatividade na criação e elaboração de Material Concreto - como sinalizam os estudos de Bacury \& Melo (2018), ao abordarem o uso desse recurso no processo de ensino e de aprendizagem da Matemática com os povos indígenas da Região do Alto Rio Negro - que favoreceu a aprendizagem dos estudantes, além do desenvolvimento do pensamento geométrico plano e aritmético. Isso ocorria quando eles eram capazes de atribuir sentido e significado às unidades de medida - o comprimento e a área - e ao perceberem as diferenças e relações entre elas, quando fizeram uso dos instrumentos matemáticos, como a régua, para traçarem os Polígonos Regulares durante os estudos.

No sentido de mobilizar e potencializar o lugar da Matemática na formação de professores e estudantes indígenas na perspectiva da Educação Matemática interdisciplinar, intercultural e intracultural, trazemos para esse processo formativo algumas das diversas práticas originárias do saber fazer na prática cotidiana, com destaque para as mulheres artesãs da comunidade Bom Caminho do povo indígena Ticuna e suas cestarias produzidas a partir das fibras extraídas das palmeiras do arumã.

As cestarias Ticuna expressam, dentre outros aspectos, todo o cotidiano do povo, da comunidade, dos indígenas, sendo a confecção desses artesanatos um momento de aprendizado e de transmissão de saberes. Evidenciam, ainda, em seus distintos traçados coloridos, um sistema próprio de linguagem, códigos, símbolos, dentre outros.

Ademais, essas práticas sociais destacam de forma implícita e explícita conhecimentos matemáticos. Principalmente quando planificamos esses cestos, podemos verificar as propriedades da Geometria Euclidiana Plana, com destaque à simetria dos traçados presentes nas muitas e variadas combinações de cores, que dão vida a essas cestarias e formam diversos Polígonos Regulares a partir dos desenhos formados da distribuição e do arranjo ao traçar uma fibra e outra de arumã.

Ao analisarmos os desenhos expressos pelas mulheres Ticuna nessas cestarias, compreendemos que é possível ensinar e aprender as matemáticas a partir de atividades tradicionais e laborais desenvolvidas por esses indígenas em seu cotidiano e em suas manifestações culturais, considerando que "ações formativas podem ser articuladas á integração da educação escolar por meio de metodologias que mobilize, nesse processo, atividades investigativas (Melo, 2016, p. 122).

$\mathrm{Na}$ perspectiva de balizarmos essas ações formativas com os professores e os estudantes indígenas, no decurso da disciplina de Fundamentos de Matemática Elementar II, recorremos à metodologia de ensino evidenciada no Geoplano para reproduzimos os Polígonos Regulares expressadas nas cestarias Ticuna, conforme mosaico ilustrado na Figura 7, a seguir. 

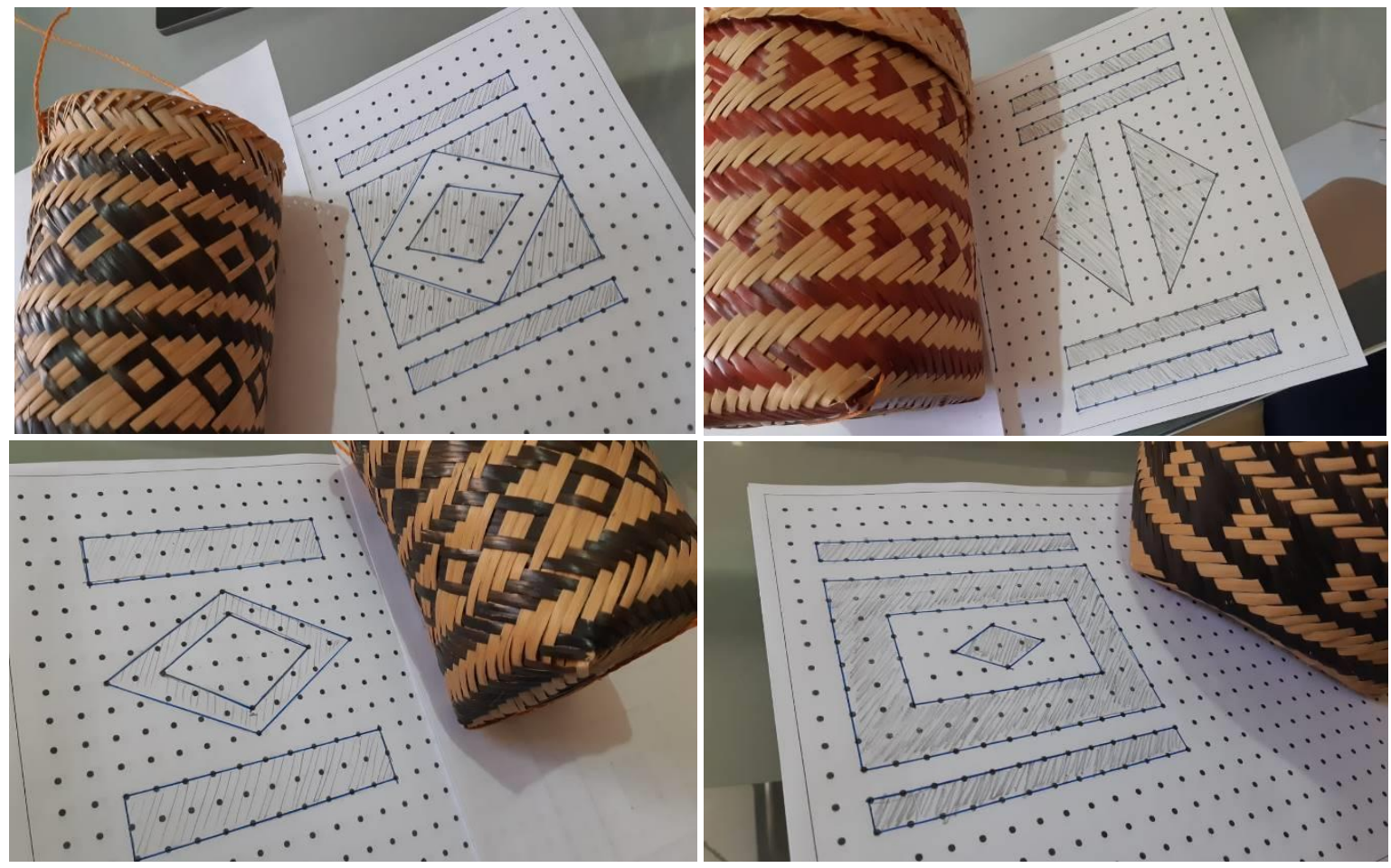

Figura 7. Planificando as figuras geométricas expressadas nas cestarias Ticuna

Fonte: Registro dos pesquisadores

$\mathrm{Na}$ sequência das atividades propostas, com o objetivo de provocarmos aprendizagens matemáticas nos estudantes, a partir de suas vivências, práticas e saberes originários evidenciados nos traçados simétricos e geométricos da cestaria Ticuna, apresentamos a reprodução via Geoplano, como evidenciado na Figura 6, dos Polígonos Regulares expressados nesses artesanatos.

Após a visualização dessas figuras, os professores e os estudantes indígenas puderam relacionar, por meio dos trançados coloridos das fibras extraídas das palmeiras do arumã, os Polígonos Regulares destacados em suas cestarias com o estudo do conteúdo de cálculo de áreas; e, ao transporem essas figuras para o Geoplano, perceberam que, ao realizarem distintas atividades laborais de seu cotidiano indígena, produziam conhecimentos matemáticos.

Contudo, muitos desses saberes culturais matemáticos não são potencializados em atividades educativas nos contextos escolares, como forma de disseminação de tais saberes. Nesse sentido, corroboramos o pensamento de Melo (2016), ao destacar que os conceitos da Matemática Escolar ainda não são considerados dentro das práticas culturais do saber fazer na prática das tradições dos povos indígenas.

Entretanto, a autora considera que ações interculturais de estudos que envolvam aspectos matemáticos revelam um fator de inovação e de criatividade, possíveis de serem mobilizados em conhecimentos disseminados, via formação indisciplinar entre os professores e seus estudantes indígenas.

Portanto, é nessa perspectiva que temos procurando atuar na formação de professores e estudantes indígenas, com objetivos de buscar as interconexões entre a Matemática Acadêmica, Escolar e do Cotidiano, como propõem David; Moreira \& Thomas (2013) e a Matemática do Cotidiano Escolar Indígena, na acepção de Bacury \& Melo (2018) nos contextos comunitários 
indígenas - entendidas como aquelas presentes e expressadas em diferentes atividades culturais e

originárias, que obedecem a um sistema próprio de linguagem e de línguas maternas, de códigos, de símbolos, dentre outros.

Assim, temos construído de forma compartilhada entre as relações de ensinar e de aprender a partir de circuitos da Educação Matemática interdisciplinar, intercultural e intracultural as matemáticas que são produzidas e existentes nos contextos comunitários indígenas, nos escolares e acadêmicos, permitindo e propiciando novos sentidos, significados e olhares para a Educação Escolar Indígena.

\section{Algumas Reflexões...}

As atuais discussões sobre a Educação Escolar Indígena abriram possibilidades para discutir e refletir a formação dos professores, assim, as Instituições Públicas de Ensino Superior passaram a ouvir, a olhar, a observar e a entender as perspectivas do movimento indígena referentes aos anseios deste em afirmar suas demandas educativas e formativas.

Dentre as expectativas formativas para os professores indígenas estão os seus quereres em adquirir os conhecimentos técnicos e científicos da academia, pautados em bases epistemológicas de diferentes campos teóricos, em metodologias que promovam o ensino e a aprendizagem interdisciplinar e intercultural, além do fomento às práticas educativas envolvendo materiais didáticos para aqueles que ensinam e que aprendem sobre o contexto político, cultural, econômico e social, para que possam ter melhores condições de vida, acesso à cidadania, fortalecimento da autonomia étnica, da gestão territorial, dentre outros. É nesse bojo de discussão, de perspectivas e de expectativas dos povos, comunidades/aldeias, professores e estudantes indígenas, que vêm ocorrendo o Curso de Licenciatura Formação de Professores Indígenas/UFAM.

No que concerne ao ensino e à aprendizagem em Matemática, empreendidas nesse curso de formação, destacamos que os indígenas almejam não somente a aquisição dos conhecimentos acadêmicos, mas também procuram a afirmação e a reafirmação de seu protagonismo, por meio de seus sistemas próprios de educação escolar, principalmente para discutir e refletir sobre a Matemática a partir dos seus distintos referenciais holísticos, que apresentam diversas matemáticas, por nós compreendidas como as Matemáticas do Cotidiano Escolar Indígena, as quais fomentam ações investigativas, mobilizadoras, problematizadas em sala de aula, entre o conteúdo matemático escolar, as práticas socioculturais e as matemáticas dos contextos comunitários desses professores e estudantes indígenas.

Ao apontarmos esses pontos de vista, o Curso de Licenciatura Formação de Professores Indígenas/UFAM nos levou a um processo de aprendizagem que tem o ensino de Matemática como lócus de novas atividades pedagógicas destinadas aos espaços educativos de suas comunidades, contemplando, assim, as ações compartilhadas de forma intracultural, intercultural e interdisciplinar, as práticas matemáticas indígenas e as escolares. O curso considerou o contexto sociocultural, que engloba os saberes e os fazeres produzidos e desenvolvidos pelos professores indígenas em formação, em especial, na área da Educação Matemática.

Os resultados provenientes da realização de diversas atividades de ensino desenvolvidas na disciplina de Fundamentos de Matemática Elementar II propiciaram aos envolvidos aprendizagens a partir do estudo de alguns conceitos da Geometria Plana. Esses processos evidenciaram interconexões entre a Matemática Acadêmica, a Matemática Escolar, a Matemática do Cotidiano; e, a partir dos contextos comunitários dos povos, a Matemática do Cotidiano Escolar Indígena.

Nessa direção, novas possibilidades foram emergindo à medida que se desenvolveram o compartilhar e o empreender de atividades matemáticas a partir da aquisição de outras formas de 
organizar as práticas pedagógicas, tanto na formação de professores indígenas quanto na atuação docente, em sala de aula com os estudantes da Educação Básica.

Todavia, ao edificar essa estrutura formativa, lembremos que os diversos contextos socioculturais fomentam conhecimentos e saberes, portanto, os processos de aprendizagens perpassam o desenvolvimento linguístico e cognitivo, que interferem de forma direta e indireta no aprendizado dos professores e dos estudantes indígenas.

Assim, as atividades desenvolvidas também se pautaram na diversidade das línguas indígenas e nas linguagens matemáticas, levando-nos a vivenciar e a experienciar o contexto comunitário da comunidade indígena Bom Caminho, para que pudéssemos criar metodologias de ensino, na perspectiva da Educação Matemática interdisciplinar, intercultural e intracultural, para abordar os conteúdos matemáticos planejados.

Nessa perspectiva, temos que o desenvolvimento da disciplina de Fundamentos de Matemática Elementar II suplantou nosso objetivo, pois propiciou aos estudantes a aquisição de novos conhecimentos, a criação, a elaboração e a proposição de atividades e práticas matemáticas interculturais e interdisciplinares. Isso ocorreu, sobretudo, a partir das discussões teóricas e das atividades realizadas, como o reconhecimento e o cálculo de área e do perímetro de Polígonos Regulares, adequado ao contexto escolar indígena, ou seja, potencializando na geração de um Material Concreto - Geoplano, no qual pode-se reproduzir os desenhos traçados com as fibras coloridas extraídas das palmeiras do arumã pelas mulheres Ticuna, nos mais variados modelos de cestarias, que compõem, dão sentidos e significados a determinados aspectos sociais e culturais da vida material dos indígenas Ticuna.

Certamente, o redimensionar da prática pedagógica possibilitou aos envolvidos desempenharem com autonomia e criatividade as suas ações docentes e também os processos de compreensão do mundo a partir das leituras matemáticas e do conhecimento tradicional indígena; em especial por consideramos as aprendizagens ocorridas por meio do estudo de alguns conceitos da Geometria Plana, como o cálculo de áreas e perímetro para os Polígonos Regulares, o Teorema de Pitágoras e as relações entre as Medidas de Superfícies.

Ademais, os obstáculos entre os estudantes e professores indígenas em formação referentes à compreensão dos termos/linguagens matemáticas empreendidas, (quanto a identificar os nomes e o emprego correto das equações para o cálculo da área e do perímetro para os Polígonos Regulares e para o cálculo do Teorema de Pitágoras) mostram-nos o quão complexo e desafiador é o processo de construção dos conhecimentos matemáticos em contextos de diversidade sociocultural e linguística, pois esses povos possuem realidades distintas, o que exige de nós, professoresformadores-pesquisadores-orientadores, que atuamos nesses espaços, uma meta de ressignificação de nossos planejamentos, práticas, dentre outros.

Mas, ao final, essas experiências configuram-se como algo recompensador, à medida que ampliam nossos horizontes ao conhecermos e aprendermos, com esses povos outras visões de mundo, levando-nos a considerar a validade de outros conhecimentos, de outras formas de construir conhecimentos e permitindo a todos os envolvidos o reconhecimento mútuo entre as culturas sem hierarquização. Em outras palavras, nossas vivências e experiências ocorridas durante a realização dessas práticas propiciaram o amplo exercício de ouvir, de esperar, de observar, de compreender e de entender, tendo como consequência falar sobre nossas experiências com práticas de Ensino de Matemática, promovendo o compartilhar de sentimentos e de diferentes histórias que em certos pontos convergem. 


\section{Referências}

Bacury, G. R.; Melo, A. P. de. (2018). Ensino e aprendizagem das matemáticas com indígenas do Alto Rio Negro/AM da Universidade Federal do Amazonas. In. Educação Matemática em Revista, Brasília, 23(60), 157-168, out./dez. 2018. Disponível em: http://www.sbem.com.br/revista/index.php/emr/article/view/1347.

Bacury, G. R. (2018). Formação inicial dos professores indígenas Mura e suas pesquisas na área de Ciências Exatas e Biológicas. In: E. A. P. de.; Melo \& G. R. Bacury (Orgs.). Diversidade sociocultural indígena: Novos olhares para a pesquisa, o ensino e a formação de professores que ensinam matemáticas (pp. 131-148). São Paulo: Editora Livraria da Física.

Bacury, G. R. (2017). Práticas investigativas na formação de futuros professores de Matemática. (Doutorado em Educação em Ciências e Matemáticas) - Universidade Federal do Pará.

Baniwa, G. (2009). Indígenas no ensino superior: Novo desafio para as organizações indígenas e indigenistas do Brasil. Revista Amazônida. Manaus, 14(02), p. 09-32.

Brasil. (2001). Lei n.10.172. Plano Nacional de Educação. Presidência da República - Casa Civil. Disponível em: http://www.planalto.gov.br/ccivil_03/leis/leis_2001/110172.htm. Acesso em: mai. de 2019.

Brasil. (2005). Secretaria de educação continuada, alfabetização e diversidade. Referencial Curricular Nacional para as Escolas Indígenas - RCNEI. 2. ed. Brasília: MEC/Secadi. Disponível em <http:// http://www.dominiopublico.gov.br/download/texto/me002078.pdf>. Acesso em: mar./2019.

Brasil. (2010). Censo demográfico. Instituto Brasileiro de Geografia e Estatística. Disponível em http://indigenas.ibge.gov.br/graficos-e-tabelas-2.html, acesso em: abr. de 2019.

Brasil. (2012). Universidade Federal do Amazonas. Projeto Político Pedagógico do curso de licenciatura formação de professores indígenas. Câmpus Manaus. Disponível em: $<$ http:// faced.ufam.edu. $\mathrm{br} /$ ensino/graduacao/formacao-de-professores-indigenas/projeto-politico-pedagogico $>$. Acesso em: mai. 2019.

Brasil. (2015). Resolução CNE/CP No 1. Brasília: Conselho Nacional de Educação, Diário Oficial da União. Disponível em: $<$ http:/ / portal.mec.gov.br/index.php?option $=$ com_docman\&view $=$ download \&alias $=16870$ res-cne-cp-001-07012015\&category_slug=janeiro-2015- pdf\&Itemid=30192 > . Acesso em: jan. 2018.

Costa, L. de F. M. da. (2018). Tramas etnomatemáticas nos cestos Ticuna. In: E. A. P. de. Melo \& G. R. Bacury (Orgs.), Diversidade sociocultural indígena: Novos olhares para a pesquisa, o ensino e a formação de professores que ensinam matemáticas (pp. 131-148). São Paulo: Editora Livraria da Física.

D’Ambrosio, U. (2004). Etnomatemática e educação: Alguns elementos de reflexão. In: G. Knijnik, F. Wanderer \& J. C. de Oliveira, J. C., Etnomatemática: Currículo e formação de professores (p. 39-52). Santa Cruz do Sul: Edunisc.

D’Ambrosio, U. (1993). A transdisciplinaridade como acesso a uma história holística. In: P. D. Well, U. D’Ambrosio, \& R. Crema (Orgs.)., Rumo à nova transdisciplinaridade: Sistemas abertos de conhecimentos (4 ed.; pp. 75-124). São Paulo: Summus.

D’Ambrosio, U. (1996). Educação matemática: Da teoria à prática. Campinas: Papirus. (Coleção Perspectivas em Educação Matemática).

D’Ambrosio, U. (2006). Educação para uma sociedade em transição. (3. ed. ver. amp.). São Paulo: Livraria da Física. (Coleção Contextos da Ciência).

David, M. M. M. S, Moreira, P. C., \& Tomaz, V. S. (2013). Matemática escolar, matemática acadêmica e matemática do cotidiano: uma teia de relações sob investigação. Acta Scientiae. 
Canoas, 15(1), 42-60. Disponível em:

<http://www.periodicos.ulbra.br/index.php/acta/article/view/349>. Acesso em: jan. 2018.

Fleuri, R. M. (2000). Desafios à educação intercultural no Brasil: Culturas diferentes podem conversar entre si? In: III Seminário de Pesquisa em Educação da Região Sul (pp. 1-15). Porto Alegre: UFRGS - ANPED - CDRom.

Gerdes, P. (2011). Mulheres, cultura e geometria na Africa Austral. Centro Moçambicano de Pesquisa em Etnomatemática. Morrisville: Lulu.

Guber, R. (2012). La etnografia: Método, campo e reflexividad. Buenos Aires: Siglo Veintiuno. (Mínina) Guidorizzi, H. L. (2007). Um curso de cálculo (v.1. $5^{\text {a }}$ ed.). reimp. Rio de Janeiro: LTC.

Ibarra, E. D. S. R., \& Souza, L. V. de S. (2016). Mulheres Tícuna: Gênero e política na Amazônia. In: Amazônica Revista Antropológica, 8(1), 90 - 117. Disponível em: https://periodicos.ufpa.br/index.php/amazonica/article/view/4726. Acesso em: mar. de 2019.

Melo, E. A. P. de. (2016). Sistema Xerente de educação matemática: Negociações entre práticas socioculturais e comunidades de prática. (Doutorado em Educação em Ciências e Matemáticas) - Universidade Federal do Pará.

Wenger, E. (2001). Comunidades de práctica: Aprendizaje, significado e identidad. Barcelona: Editorial Paidos.

\section{Sobre os Autores}

\section{Elisângela Aparecida Pereira de Melo}

Universidade Federal do Tocantins (UFT)

elisangelamelo@uft.edu.br

https://orcid.org/0000-0001-6827-0566

Possui Doutorado em Educação em Ciências e Matemáticas pela Universidade Federal do Pará (UFPA); Mestrado em Educação pelo Programa de Pós-graduação em Educação, linha de pesquisa Educação Matemática, da Universidade Federal do Rio Grande do Norte (UFRN); Graduada em Licenciatura em Matemática pela Universidade do Estado do Tocantins (Unitins); Professora do Curso de Licenciatura em Matemática da Universidade Federal do Tocantins (UFT)/Câmpus de Araguaína; Professora pesquisadora do Programa de Pós-graduação em Ensino de Ciências e Matemática (PPGECIM/Câmpus de Araguaína). Líder do Grupo de Estudos e Pesquisa Grupo de Pesquisa em Sistemas Socioculturais de Educação Matemática (SisMat)/UFT; Membra do Grupo de Estudos e Pesquisa de Práticas Investigativas em Educação Matemática (GEPIMat)/UFAM e Tutora do Grupo PET/Conexões de Saberes Indígenas.

\section{Gerson Ribeiro Bacury}

Universidade Federal do Amazonas (UFAM)

gersonbacury@gmail.com

https://orcid.org/0000-0002-1160-3187

Possui Doutorado em Educação em Ciências e Matemática pela Universidade Federal do Pará (UFPA); Mestrado em Educação pelo Programa de Pós-graduação em Educação da Faculdade de Educação da Universidade Federal do Amazonas (UFAM); Graduado em Licenciatura em Matemática pela Universidade Federal do Amazonas (UFAM); Professor do Curso de Licenciatura Formação de Professores Indígenas da Universidade Federal do Amazonas (UFAM)/Câmpus de Manaus; Professor pesquisador do Programa de Pós-graduação em 
Educação (PPGE)/UFAM; Líder do Grupo de Estudos e Pesquisa de Práticas Investigativas em Educação Matemática (GEPIMat)/UFAM; Membro do Grupo de Estudos e Pesquisa Grupo de Pesquisa em Sistemas Socioculturais de Educação Matemática (SisMat)/UFT.

\section{Pedro Ferreira da Silva}

Universidade Federal do Amazonas (UFAM)

pedroferreirabc01@gmail.com

https://orcid.org/0000-0001-5081-0763

Estudante do Curso de Licenciatura em Formação de Professores Indígenas da Universidade Federal do Amazonas (UFAM)/Polo de Benjamin Constant/AM. Pertence ao povo indígena Tícuna - da Nação do Boi - Wewemücü, da Região do Alto Solimões/AM.

\section{Domingos Anselmo Moura da Silva}

Universidade Federal do Amazonas (UFAM)

ufam.anselmo@gmail.com

https://orcid.org/0000-0003-1978-5357

Possui Mestrado em Matemática Pura na Área de Geometria Diferencial pela Universidade Federal do Amazonas (UFAM); Graduado em Licenciatura e Bacharelado em Matemática pela Universidade Federal do Amazonas (UFAM); Professor do Curso de Licenciatura e Bacharelado em Matemática Pura e Aplicada da Universidade Federal do Amazonas; Membro do Grupo de Estudos e Pesquisa de Práticas Investigativas em Educação Matemática (GEPIMat)/UFAM.

\section{Sobre o Editores}

\section{Juliane Sachser Angnes}

Universidade Estadual do Centro-Oeste do Paraná (UNICENTRO)

Programa de Pós-Graduação em Educação (PPGE UNICENTRO)

Programa de Pós-Graduação em Administração (PPGADM UNICENTRO)

julianeangnes@gmail.com

https://orcid.org/0000-0002-4887-7042

Graduação em Secretariado Executivo Bilíngue e em Letras - Português/Inglês pela

Universidade Estadual do Oeste do Paraná (UNIOESTE). Especialista em Linguística Aplicada e Mestre em Letras - Linguagem e Sociedade também pela UNIOESTE. Doutora em Educação pela Universidade Federal do Paraná (UFPR), linha de Cognição, Desenvolvimento Humano e Aprendizagem. Realizou estágio pós-doutoral no Programa de Pós-Graduação em Administração da Universidade Estadual de Maringá (UEM) no Grupo de Pesquisas em Estudos Organizacionais. É professora da Universidade Estadual do Centro-Oeste (UNICENTRO) vinculada ao Departamento de Secretariado Executivo e ao Programa de PósGraduação em Administração (Mestrado Profissional). Tem experiência na docência e pesquisa nas áreas de Educação e Administração, atuando principalmente nas seguintes áreas temáticas: comunicação organizacional; redes solidárias; economia do bem-estar social; gestão escolar; planejamento e organização de eventos; cerimonial e protocolo; etiqueta social e comportamental; redação técnica oficial e empresarial; responsabilidade social; pesquisa qualitativa em Ciências Sociais Aplicadas. É Líder do Grupo de Pesquisas em Gestão do Conhecimento da Universidade Estadual do Centro-Oeste do Paraná. É líder do grupo de pesquisa em Gestão do Conhecimento. 


\section{Kaizô Iwakami Beltrão}

EBAPE FGV - - Escola Brasileira de Administração Pública e de Empresas

Kaizo.beltrao@,fgv.br

http://orcid.org/0000-0002-3590-8057

Graduação em Engenharia Mecânica pelo Instituto Tecnológico de Aeronáutica (1974), mestrado em Matemática Aplicada pelo Instituto de Matemática Pura e Aplicada (1977) e doutorado em Estatística pelo Departamento de Estatística da Princeton University (1981). Atualmente é Pesquisador/Professor da EBAPE/FGV-RJ e responsável técnico pelos relatórios técnicos do ENADE junto ao INEP através da Fundação Cesgranrio. Tem experiência na área de População e Políticas Públicas, com ênfase em Previdência Social e Educação, atuando principalmente nos seguintes temas: bases de dados para políticas públicas, avaliações educacionais, diferenciais por sexo/raça, condições de saúde, demografia (modelagem estatística) e mortalidade.

\section{Dossiê Especial \\ Educação e Povos Indígenas: Identidades em Construção e Reconstrução arquivos analíticos de políticas educativas}

Volume 28 Número 81
11 de maio 2020
ISSN 1068-2341

\section{(9) (1) (-)} siempre y cuando se de crédito y atribución al autor/es y a Archivos Analíticos de Políticas Educativas, los cambios se identifican y la misma licencia se aplica al trabajo derivada. Más detalles de la licencia de Creative Commons se encuentran en https://creativecommons.org/licenses/bysa/2.0/. Cualquier otro uso debe ser aprobado en conjunto por el autor/es, o AAPE/EPAA. La sección en español para Sud América de AAPE/EPAA es publicada por el Mary Lou Fulton Teachers College, Arizona State University y la Universidad de San Andrés de Argentina. Los artículos que aparecen en AAPE son indexados en CIRC (Clasificación Integrada de Revistas Científicas, España) DIALNET (España), Directory of Open Access Journals, EBSCO Education Research Complete, ERIC, Education Full Text (H.W. Wilson), PubMed, QUALIS A1 (Brazil), Redalyc, SCImago Journal Rank, SCOPUS, SOCOLAR (China).

Por errores y sugerencias contacte a Fischman@asu.edu

Síganos en EPAA's Facebook comunidad at https://www.facebook.com/EPAAAAPE y en Twitter feed@epaa_aape 


\section{arquivos analíticos de políticas educativas conselho editorial}

Editor Consultor: Gustavo E. Fischman (Arizona State University)

Editoras Associadas: Andréa Barbosa Gouveia (Universidade Federal do Paraná), Kaizo Iwakami Beltrao, (Brazilian School of Public and Private Management - EBAPE/FGVl), Sheizi Calheira de Freitas (Federal University of Bahia), Maria Margarida Machado, (Federal University of Goiás / Universidade Federal de Goiás), Gilberto José Miranda, (Universidade Federal de Uberlândia, Brazil), Marcia Pletsch (Universidade Federal Rural do Rio de Janeiro), Maria Lúcia Rodrigues Muller (Universidade Federal de Mato Grosso e Science), Sandra Regina Sales (Universidade Federal Rural do Rio de Janeiro)

\begin{abstract}
Almerindo Afonso
Universidade do Minho

Portugal
\end{abstract}

\section{Rosanna Maria Barros Sá}

Universidade do Algarve

Portugal

Maria Helena Bonilla

Universidade Federal da Bahia

Brasil

\section{Rosa Maria Bueno Fischer}

Universidade Federal do Rio Grande do Sul, Brasil

\section{Alice Casimiro Lopes \\ Universidade do Estado do Rio de \\ Janeiro, Brasil}

\section{Suzana Feldens Schwertner}

Centro Universitário Univates

Brasil

\section{Geovana Mendonça Lunardi}

Mendes Universidade do Estado de Santa Catarina

\section{Flávia Miller Naethe Motta}

Universidade Federal Rural do Rio de Janeiro, Brasil

\section{Alexandre Fernandez Vaz \\ Universidade Federal de Santa \\ Catarina, Brasil \\ Regina Célia Linhares Hostins \\ Universidade do Vale do Itajaí, Brasil}

\section{Alfredo Macedo Gomes \\ Universidade Federal de Pernambuco \\ Brasil}

\section{Jefferson Mainardes}

Universidade Estadual de Ponta

Grossa, Brasil

Jader Janer Moreira Lopes

Universidade Federal Fluminense e

Universidade Federal de Juiz de Fora, Brasil

\section{Debora Nunes}

Universidade Federal do Rio Grande do Norte, Brasil

\section{Alda Junqueira Marin}

Pontifícia Universidade Católica de São Paulo, Brasil

\section{Dalila Andrade Oliveira}

Universidade Federal de Minas

Gerais, Brasil
José Augusto Pacheco

Universidade do Minho, Portugal

\section{Jane Paiva}

Universidade do Estado do Rio de

Janeiro, Brasil

Paulo Alberto Santos Vieira

Universidade do Estado de Mato

Grosso, Brasil

Fabiany de Cássia Tavares Silva

Universidade Federal do Mato

Grosso do Sul, Brasil

\section{António Teodoro}

Universidade Lusófona

Portugal

Lílian do Valle

Universidade do Estado do Rio de Janeiro, Brasil

\section{Alfredo Veiga-Neto}

Universidade Federal do Rio Grande do Sul, Brasil 


\section{archivos analíticos de políticas educativas consejo editorial}

Editor Consultor: Gustavo E. Fischman (Arizona State University)

Editores Asociados: Felicitas Acosta (Universidad Nacional de General Sarmiento), Armando Alcántara Santuario (Universidad Nacional Autónoma de México), Ignacio Barrenechea, Jason Beech (Universidad de San Andrés), Angelica Buendia, (Metropolitan Autonomous University), Alejandra Falabella (Universidad Alberto Hurtado, Chile), Carmuca Gómez-Bueno (Universidad de Granada), Veronica Gottau (Universidad Torcuato Di Tella),

Carolina Guzmán-Valenzuela (Universidade de Chile), Antonia Lozano-Díaz (University of Almería), Antonio

Luzon, (Universidad de Granada), María Teresa Martín Palomo (University of Almería), María Fernández Mellizo-

Soto (Universidad Complutense de Madrid), Tiburcio Moreno (Autonomous Metropolitan University-Cuajimalpa Unit), José Luis Ramírez, (Universidad de Sonora), Axel Rivas (Universidad de San Andrés), César Lorenzo

Rodríguez Uribe (Universidad Marista de Guadalajara), Maria Veronica Santelices (Pontificia Universidad Católica de Chile)

Claudio Almonacid

Universidad Metropolitana de

Ciencias de la Educación, Chile

\section{Miguel Ángel Arias Ortega}

Universidad Autónoma de la

Ciudad de México

Xavier Besalú Costa

Universitat de Girona, España

Xavier Bonal Sarro Universidad

Autónoma de Barcelona, España

Antonio Bolívar Boitia

Universidad de Granada, España

José Joaquín Brunner Universidad Diego Portales, Chile

Damián Canales Sánchez

Instituto Nacional para la

Evaluación de la Educación,

México

\section{Gabriela de la Cruz Flores}

Universidad Nacional Autónoma de

México

Marco Antonio Delgado Fuentes

Universidad Iberoamericana,

México

Inés Dussel, DIE-CINVESTAV, México

Pedro Flores Crespo Universidad Iberoamericana, México
Ana María García de Fanelli

Centro de Estudios de Estado y

Sociedad (CEDES) CONICET,

Argentina

Juan Carlos González Faraco

Universidad de Huelva, España

María Clemente Linuesa

Universidad de Salamanca, España

Jaume Martínez Bonafé

Universitat de València, España

Alejandro Márquez Jiménez

Instituto de Investigaciones sobre la

Universidad y la Educación,

UNAM, México

María Guadalupe Olivier Tellez, Universidad Pedagógica Nacional, México

Miguel Pereyra Universidad de

Granada, España

Mónica Pini Universidad Nacional de San Martín, Argentina

Omar Orlando Pulido Chaves Instituto para la Investigación Educativa y el Desarrollo Pedagógico (IDEP)

José Ignacio Rivas Flores

Universidad de Málaga, España
Miriam Rodríguez Vargas

Universidad Autónoma de

Tamaulipas, México

José Gregorio Rodríguez

Universidad Nacional de Colombia, Colombia

Mario Rueda Beltrán Instituto de Investigaciones sobre la Universidad y la Educación, UNAM, México José Luis San Fabián Maroto Universidad de Oviedo, España

Jurjo Torres Santomé, Universidad de la Coruña, España

Yengny Marisol Silva Laya

Universidad Iberoamericana, México

Ernesto Treviño Ronzón Universidad Veracruzana, México

Ernesto Treviño Villarreal Universidad Diego Portales Santiago, Chile

Antoni Verger Planells Universidad Autónoma de Barcelona, España

Catalina Wainerman Universidad de San Andrés, Argentina

Juan Carlos Yáñez Velazco Universidad de Colima, México 


\section{education policy analysis archives editorial board}

Lead Editor: Audrey Amrein-Beardsley (Arizona State University)

Editor Consultor: Gustavo E. Fischman (Arizona State University)

Associate Editors: Melanie Bertrand, David Carlson, Lauren Harris, Eugene Judson, Mirka Koro-Ljungberg, Daniel Liou, Scott Marley, Molly Ott, Iveta Silova (Arizona State University)

Cristina Alfaro

San Diego State University

Gary Anderson

New York University

Michael W. Apple

University of Wisconsin, Madison

Jeff Bale

University of Toronto, Canada

Aaron Bevenot SUNY Albany

David C. Berliner

Arizona State University

Henry Braun Boston College

\section{Casey Cobb}

University of Connecticut

Arnold Danzig

San Jose State University

Linda Darling-Hammond

Stanford University

Elizabeth H. DeBray

University of Georgia

David E. DeMatthews

University of Texas at Austin

Chad d'Entremont Rennie Center

for Education Research \& Policy

John Diamond

University of Wisconsin, Madison

Matthew Di Carlo

Albert Shanker Institute

Sherman Dorn

Arizona State University

Michael J. Dumas

University of California, Berkeley

Kathy Escamilla

University ofColorado, Boulder

Yariv Feniger Ben-Gurion

University of the Negev

Melissa Lynn Freeman

Adams State College

Rachael Gabriel

University of Connecticut
Amy Garrett Dikkers University

of North Carolina, Wilmington

Gene V Glass

Arizona State University

Ronald Glass University of

California, Santa Cruz

Jacob P. K. Gross

University of Louisville

Eric M. Haas WestEd

Julian Vasquez Heilig California

State University, Sacramento

Kimberly Kappler Hewitt

University of North Carolina

Greensboro

Aimee Howley Ohio University

Steve Klees University of Maryland

Jaekyung Lee SUNY Buffalo

Jessica Nina Lester

Indiana University

Amanda E. Lewis University of

Illinois, Chicago

Chad R. Lochmiller Indiana

University

Christopher Lubienski Indiana

University

Sarah Lubienski Indiana University

William J. Mathis

University of Colorado, Boulder

Michele S. Moses

University of Colorado, Boulder

Julianne Moss

Deakin University, Australia

Sharon Nichols

University of Texas, San Antonio

Eric Parsons

University of Missouri-Columbia

Amanda U. Potterton

University of Kentucky

Susan L. Robertson

Bristol University
Gloria M. Rodriguez

University of California, Davis

R. Anthony Rolle

University of Houston

A. G. Rud

Washington State University

Patricia Sánchez University of

University of Texas, San Antonio

Janelle Scott University of

California, Berkeley

Jack Schneider University of

Massachusetts Lowell

Noah Sobe Loyola University

Nelly P. Stromquist

University of Maryland

Benjamin Superfine

University of Illinois, Chicago

Adai Tefera

Virginia Commonwealth University

A. Chris Torres

Michigan State University

Tina Trujillo

University of California, Berkeley

Federico R. Waitoller

University of Illinois, Chicago

Larisa Warhol

University of Connecticut

John Weathers University of

Colorado, Colorado Springs

Kevin Welner

University of Colorado, Boulder

Terrence G. Wiley

Center for Applied Linguistics

John Willinsky

Stanford University

Jennifer R. Wolgemuth

University of South Florida

Kyo Yamashiro

Claremont Graduate University

Miri Yemini

Tel Aviv University, Israel 